\title{
Selection Strategy of In Vivo Models for Ophthalmic Drug Development in Diabetic Retinopathy
}

Reyns Geert $\mathrm{E}^{1 \#}$, Hu Tjing-Tjing ${ }^{1 \#}$, Van Bergen Tine ${ }^{1 \#}$, Etienne Isabelle ${ }^{1}$, Willekens Koen ${ }^{2}$, Jonckx Bart ${ }^{1}$ and Feyen Jean HM ${ }^{1^{*}}$

${ }^{1}$ ThromboGenics N.V., Gaston Geenslaan 1, 3001 Leuven, Belgium

${ }^{2}$ Department of Ophthalmology, University Hospitals Leuven, 3000 Leuven, Belgium

\#Authors with equal contribution

"Corresponding author: Jean H.M. Feyen, ThromboGenics NV, Gaston Geenslaan 1, B-3001, Heverlee, Belgium, Tel: 3216751451; Fax: 321671311; E-mail: jean.feyen@thrombogenics.com

Received date: January 18, 2016; Accepted date: January 25, 2016; Published date: January 30, 2016

Copyright: ( 2016 Reyns GE, et al. This is an open-access article distributed under the terms of the Creative Commons Attribution License, which permits unrestricted use, distribution, and reproduction in any medium, provided the original author and source are credited.

\begin{abstract}
Diabetic Retinopathy (DR) is the most common microvascular complication of diabetes and is one of the leading causes of visual impairment worldwide. DR is a chronic eye disease that eventually can result in legal blindness due to the evolution towards the major vision-threatening disorders diabetic macular edema (DME) and/or proliferative diabetic retinopathy (PDR). Current treatments with steroids, anti-VEGF compounds or retinal laser photocoagulation have shown a significant improvement in visual acuity in the advanced stage of the disease. However, main concerns are possible side effects and/or the relatively large number of clinical non-responders. A better understanding of the biological and molecular pathways not only in DR patients but also in the preclinical in vivo models would aid the development of novel and more efficient (personalized) therapeutic approaches for DR. This review aims to describe the pathways in a selection of diabetic, non-diabetic and surrogate rodent models of pathogenic neovascularization, vascular permeability, inflammation and neurodegeneration. None of these models can mimic the entire human pathophysiological progression but they all exhibit joint pathophysiological features with human DR pathogenesis. These combined features make these models very relevant in gaining a better understanding of the disease etiology and eventually improved strategies for drug screening. Through highlighting the most important biochemical and molecular pathways that these animal models have in common with DR patients, selection of the most suitable model for mechanistic studies and drug screening can be facilitated.
\end{abstract}

Keywords: Diabetic retinopathy; Rodent models; Biochemical pathways; Personalized therapy

\section{Introduction}

Diabetes mellitus is rapidly becoming one of the most important diseases of the modern world. Diabetic retinopathy (DR) is a common complication of diabetes. It affects 1 out of 3 persons with diabetes and it refers to a group of eye problems that is caused by damage of blood vessels inside the retina. The severity of DR ranges from nonproliferative (NPDR), the early stage of $\mathrm{DR}$, to more severely proliferative DR (PDR) in which the abnormal growth of new vessels occurs, due to progressive capillary endothelial cell damage, retinal ischemia and neovascularization [1]. Moderate vision loss from diabetic macular edema (DME) is a common hallmark of the disease. Severe vision loss and blindness can occur in subjects with retinal detachment and vitreous hemorrhages resulting from severe fibrovascular contractions [2]. Besides the abnormalities in the retinal capillary bed located in the inner retina (microangiopathy), complications in the neural retina (retinal neurodegeneration) occur as well in DR. Indeed, it has become generally accepted that essential DRrelated microvascular alterations such as loss of pericytes, basement membrane thickening, blood-retinal barrier (BRB) breakdown and neovascularization are interlinked with neurodegeneration processes, which are characterized by neural apoptosis and glial dysfunction $[3,4]$.
Current therapies of advanced DR consist of laser photocoagulation or intravitreal injections of steroids and vascular endothelial growth factor (VEGF) inhibitors. Laser treatment, the standard of care for DR, is reducing the retina's oxygen demand and is a highly effective for preventing further visual loss in diabetic patients [5]. However, this invasive method usually does not restore nor improve vision and can be associated with visual field loss. The use of corticosteroids is based on their pleiotropism as anti-inflammatory, anti-angiogenic, and antipermeability agent [6,7]. In edematous and proliferative diseases such as DR, abnormal proliferation of cells is often associated with and trigged by inflammation. However, the exact working mechanisms of corticosteroids remain largely unknown to date and they have side effects such as intraocular pressure (IOP) elevation and cataract formation [8-10].

Over the last years, anti-VEGF injections are becoming the preferred treatment option for DME [11,12] as well as PDR [13]. Ranibizumab (Lucentis ${ }^{\circ}$, Genentech, an anti-VEGF antibody fragment (Fab)) $[14,15]$, and aflibercept (Eylea ${ }^{\circ}$, Bayer, an anti-VEGF fusion protein containing the extracellular binding domains of human VEGF receptors 1 and 2) [16,17] were recently approved for treatment of DR in patients with DME. Bevacizumab (Avastin ${ }^{\oplus}$, Genentech Inc., a humanized monoclonal antibody against VEGF-A) [18,19], approved for several oncologic conditions, is used as an "off-label" therapy in ophthalmology [20]. Although several adverse events are reported for the anti-VEGF therapies, including cataract formation, endophthalmitis, vitreous hemorrhage and retinal detachment, they are relatively well tolerated and overall considered safe $[21,22]$. The 
impact of long-term administration of anti-VEGF agents on events such as geographic atrophy, hypertension, increased IOP, proteinuria, increased cardiovascular events and impaired wound healing remains to be carefully evaluated $[23,24]$. Finally, potential inhibition of the neuroprotective effect of VEGF is another clinically relevant concern since more and more people concomitantly develop DR and glaucoma, due to the aging of the population [25]. Since retinal ganglion cell loss is the main feature in glaucoma patients, an alternative treatment beyond anti-VEGF should be considered in subjects suffering from coexisting glaucoma and retinal diseases.

Although the new therapies show great efficacy, the results of major clinical trials also indicate that there is a substantial variation in the clinical response in patients with DR and DME. Around 50 to $60 \%$ of the patients treated with VEGF inhibitors [26-32] or steroids [10,33] do not demonstrate satisfactory levels of visual acuity improvement and are known as non-responders. The outcome of these clinical observations is indicative for multifactorial processes in the pathogenesis of DME, and many other factors beyond VEGF may play a role in this process. The complexity of the manifestation of the disease is exemplified by the recognition of three phenotypic disease patterns. These phenotypes are mainly characterized by different dominant retinal alterations and different rates of progression using non-invasive imaging methods as spectral domain-optical coherence tomography (SD-OCT) and multifocal electroretinography (ERG) [34-36]. Pattern A, a slow progression type, includes eyes with reversible and relatively little abnormal leakage, a slow rate of microaneurysm formation and a normal foveal avascular zone. Pattern B is characterized as a 'wet' form of DR and includes eyes with high levels of leakage, indicating important alterations in the BRB. This phenotype is also associated with neuroglial damage and inflammation. Pattern C, the ischemic type, includes eyes showing variable leakage but active remodeling of the retinal microcirculation with signs of capillary closure.

At the biochemical level, the disease complexity is demonstrated by the heterogeneity in composition of vitreo-retinal compartment during the development of the different stages of DR. Both quantitative and qualitative differences have been reported for structural components (e.g. fibrinogen [37], transthyretin, clusterin and crystallin [38], apolipoprotein $\mathrm{H}[39,40]$ ), growth factors (e.g. insulin-like growth factor 1 (IGF-1) and IGF-binding proteins 2 and 5 [41,42], pigment epithelium-derived factor [43], complement C3 [37,39]), cytokines/ chemokines (e.g. interleukin (IL)-6, IL-8, IL-10, monocyte chemoattractant protein-1 (MCP-1) $[44,45])$ and plasma kallikrein (PKal) [46] in the vitreo-retinal compartment. Differences in progression of diabetic retinal disease are generally accepted to be conditioned by a variety of different genetic polymorphisms [47]. Unraveling the relationships between genetic factors (genotypes) and their clinical expression (phenotypes) can provide crucial information for personalized therapy. This tailored therapeutic approach in DR is an emerging trend aimed at achieving maximum therapeutic response in patients that do not demonstrate an optimal response to current therapies [48-50].

Throughout the years, many animal models of DR have been developed. The disease onset and pathways involved may differ dependent on the species, genetic background of a particular animal strain, and the trigger to induce the disease. None of these models are able to mimic the entire pathophysiological progression of DR as observed in human. Therefore researchers often have to select complementary models in order to obtain a comprehensive view on the impact of drugs or candidate drugs on the disease process. The main purpose of this review is not to have a complete list of all potential DR animal models and read-out techniques as other recent reviews on animal models for DR have already covered this [51-53]. The focus of this review is to provide new insights in the relevance of a selection of animal models for DR drug profiling by highlighting the most important pathophysiological pathways and biochemical mechanisms that these animal models have in common with DR patients. In addition, model significance in drug efficacy screening is illustrated by a few examples.

\section{Selection of Rodent Models}

Various animal models have been developed to investigate the underlying mechanisms of sight-threatening pathologies, such as DR and possible new targets. Among the different animal species used in these models, most laboratory animals are rodents. Moreover, a rodent model is practically imperative to explore new potential therapeutics in a diabetic context given that diabetic models in higher mammals are not well defined and very scarce to non-existing.

\begin{tabular}{|c|c|c|c|}
\hline & Rodent model & $\begin{array}{l}\text { Biochemical } \\
\text { pathways }\end{array}$ & Morphological events \\
\hline \multirow[t]{2}{*}{$\begin{array}{l}\text { Diabetic } \\
\text { models }\end{array}$} & STZ & $\begin{array}{l}\text { PKC activation } \\
\text { Polyol } \\
\text { AGE } \\
\text { Oxidative stress } \\
\text { Inflammation }\end{array}$ & $\begin{array}{l}\text { Neovascularization } \\
\text { Vascular leakage } \\
\text { Neurodegeneration } \\
\text { Fibrosis }\end{array}$ \\
\hline & Akimba & $\begin{array}{l}\text { Hypoxia } \\
\text { Inflammation }\end{array}$ & $\begin{array}{l}\text { Neovascularization } \\
\text { Vascular leakage } \\
\text { Neurodegeneration } \\
\text { Fibrosis }\end{array}$ \\
\hline \multirow[t]{5}{*}{$\begin{array}{l}\text { Surrogate } \\
\text { models }\end{array}$} & CNV & $\begin{array}{l}\text { AGE } \\
\text { Oxidative stress } \\
\text { Inflammation }\end{array}$ & $\begin{array}{l}\text { Neovascularization } \\
\text { Vascular leakage } \\
\text { Fibrosis }\end{array}$ \\
\hline & OIR & $\begin{array}{l}\text { Hypoxia } \\
\text { Inflammation }\end{array}$ & $\begin{array}{l}\text { Neovascularization } \\
\text { Vascular leakage } \\
\text { Neurodegeneration }\end{array}$ \\
\hline & VEGF-injection & $\begin{array}{l}\text { PKC activation } \\
\text { Hypoxia } \\
\text { Inflammation }\end{array}$ & $\begin{array}{l}\text { Neovascularization } \\
\text { Vascular leakage }\end{array}$ \\
\hline & Paw edema & $\begin{array}{l}\text { Oxidative stress } \\
\text { Inflammation }\end{array}$ & Vascular leakage \\
\hline & $\begin{array}{l}\text { Skin } \\
\text { permeability }\end{array}$ & Inflammation & Vascular leakage \\
\hline
\end{tabular}

Table 1: An overview of DR-related biochemical pathways and morphological events involved in preclinical rodent models. DR pathways which are not included are not affected or not investigated in the animal model.

This review describes a subset of rodent models which are frequently used to investigate vascular permeability and/or angiogenesis, the two main vision-threatening pathogenic hallmarks of DR (respectively corresponding to DME and PDR). On the one hand, 
there are the surrogate non-diabetic ocular models, such as the laser induced choroidal neovascularization $(\mathrm{CNV})$, oxygen induced retinopathy (OIR) and VEGF-induced permeability model. Also nondiabetic non-ocular models exist, such as paw edema and skin permeability models. All these acute non-diabetic models are highly reproducible and effective, have a higher throughput and large induction window. On the other hand, there are the diabetic-ocular models, such as the chemically streptozotocin (STZ)-induced and the transgenic models (e.g. Akimba). These models are more representative for the long-term human disease. However, none of them can mimic the entire pathophysiological progression as observed in human (Table 1).

Noteworthy, the models in this review are limited to species in which the authors have gained considerable experience, and some of the models have been described in mouse as well as in rat, e.g. models of choroidal neovascularization and retinopathy of prematurity [54]. Once the models are introduced, the different biochemical pathways involved in the disease development are described followed by more technical details of the model such as the different read-out techniques available (Table 2).

\begin{tabular}{|l|l|}
\hline Animal model & Read-out technique(s) \\
\hline Mouse CNV & $\begin{array}{l}\text { FITC-dextran perfused choroidal } \\
\text { flatmount; Fluorescein angiography; } \\
\text { SD-OCT }\end{array}$ \\
\hline Mouse OIR & $\begin{array}{l}\text { Histology (H\&E); } \\
\text { Isolectin B4 stained retinal flatmount }\end{array}$ \\
\hline $\begin{array}{l}\text { Mouse retinal } \\
\text { permeability }\end{array}$ & SD-OCT \\
\hline Rat VEGF-induced retinal permeability & Fluorophotometry \\
\hline Rodent skin permeability & Evans Blue perfusion \\
\hline Rat paw edema & Plethysmography \\
\hline Mouse STZ-induced diabetes & FITC-BSA perfusion \\
\hline Rat STZ-induced diabetes & $\begin{array}{l}\text { FITC-BSA perfusion; } \\
\text { Fluorophotometry }\end{array}$ \\
\hline Diabetic Akimba mouse & $\begin{array}{l}\text { Fluorescein angiography; } \\
\text { Spectral domain-Optical coherence } \\
\text { tomography; } \\
\text { FITC-BSA perfused retinal flatmount; } \\
\text { Histology and Immunohistochemistry }\end{array}$ \\
\hline
\end{tabular}

Table 2: Read-out techniques available for the different animal models.

\section{Diabetic models}

Chemically-induced streptozotocin models: Diabetes can be induced by injection of streptozotocin (STZ) or alloxan. These chemicals are particularly toxic to the pancreatic $\beta$-cells and result in insulin deficiency and systemic hyperglycemia. STZ mice and rats are one of the most popular induced diabetic models and have been routinely used in fundamental studies and therapeutic drug experiments. Depending on the injection dosage, the onset of diabetes can be achieved within a few days after injection for rats and mice become hyperglycemic in 1 to 4 weeks after STZ injection. Compared to mice, rats are more susceptible to the toxicity of STZ; therefore, usually a much lower dosage of STZ is used [53].

Biochemical and molecular pathways: DR is characterized by an intricate meshwork of various pathologic pathways and this complexity is only partially reflected in the STZ-induced diabetic rodent model. Besides hyperglycemia several other diabetes-related disease mechanisms such as oxidative stress [55,56], retinal inflammation [56-61], protein kinase C (PKC) activation [62,63], Polyol \& advanced glycation endproducts (AGE) pathway [64-66], neural dysfunction $[67,68]$ and vascular dysfunction [51,69-77] can be studied in this chemically-induced diabetes animal model.

The (micro)vascular complications are the best investigated characteristics in the STZ rodent model in the context of DR/DME. The retinas in STZ-induced diabetic rodents exhibit most of the vascular pathological features of $\mathrm{DR}$, including blood vessel dilation, BRB breakdown, microaneurysm formation, intraretinal microvascular abnormalities [71], thickening of endothelial basement membrane [51,72] and pericyte loss [74,76]. Most importantly, it is known that increased vascular leakage can occur in the STZ rodent model $[69,73]$. One of the most important factor that has been investigated extensively in relation to retinal permeability is VEGF. It is known that VEGF and its receptors are upregulated over time in the STZ rat model [78-80].

Moreover, different groups have already shown in STZ models that VEGF-Trap administration, either subcutaneous, intravenous or intravitreal, is able to significantly reduce permeability $[81,82]$ and decrease intracellular adhesion molecule-1 (ICAM-1), endothelial NOS (eNOS) and nitric oxide (NO) levels in the diabetic retina [57]. In rat STZ model, increased vascular permeability can also be inhibited by administration of an matrix metalloproteinase (MMP) inhibitor, through the proteolytic degradation of vascular endothelial (VE)cadherin [83]. It is known that high glucose can activate many soluble mediators such as AGE, reactive oxygen species (ROS), and inflammatory cytokines, which can increase MMP expression and activity in a diabetic state. Also the inhibition of angiostatin is known to reduce vascular leakage in the STZ model [84].

Despite the fact that it is described that in diabetic mice and rats the retinal blood flow is markedly reduced compared to control nondiabetic rats $[77,85]$, no proof of retinal hypoxia is available in the STZ rodent model. Indeed, hypoxia-inducible factor (HIF) levels in STZinjected mouse $(\mathrm{C} 57 \mathrm{BL} / 6)$ and rat (Wistar) retinas appeared to be similar to their respective control [85]. Interestingly, neovascularization has been reported in STZ-induced mice [86], whereas angiogenesis has never been observed in the rat STZ model [51-53,71].

Besides these vascular dysfunctions, other pathologic pathways also play a major role in STZ-induced retinopathy. In turn, these underlying mechanisms of DR are all directly or indirectly associated with the vascular complications and in these complex interactions it is not clear-cut which pathway is cause or consequence. It is generally accepted that activation of the PKC pathway in the retina of diabetic STZ animals can regulate the development of abnormal retinal hemodynamics [62,63]. Several studies have also described the presence of oxidative stress in the rodent STZ model but retinal oxidative stress and the hyperglycemia-associated formation of ROS can be prevented by the orally administered aldose reductase inhibitor fidarestat [55] as well as the topically applied (eye drop) kinin B1 receptor antagonist LF22-0542 [56]. 
Moreover, the latter inhibitor can also impede retinal inflammation in STZ-diabetic rats, which implies that in this chemically-induced animal model different pathologic pathways are intertwined as well, mirroring the clinical DR situation. Many research groups have indeed implicated inflammatory mediators such as tumor necrosis factor (TNF)- $\alpha$ [58], IL-1 $\beta$ [60], IL-6 [87], ICAM-1 [57], MCP-1 [59], PKal and bradykinin [56] as major drivers in the pathogenesis of DR and DME. In corroboration with these inflammation-related findings, leukostasis has been observed in the mouse STZ [77] as well as the rat STZ model $[88,89]$. Diabetes-dependent hyperglycemia can induce the polyol (sorbitol) pathway by activation of the metabolic enzyme aldose reductase and it has been scrutinized in diabetic STZ rats that the polyol pathway can lead to retinal vascular abnormalities, cell death and the formation of ROS [55,66]. Of note, lower activity of aldose reductase in mice compared to rat has been described, resulting in relative protection against developing retinopathy [90]. In addition, the intermediate metabolites of the polyol pathway can contribute to the formation of AGEs in diabetic tissues [91] and numerous findings have implicated the AGE-RAGE pathway in the pathogenesis of DR $[59,64,92,93]$.

Finally, recent studies also stress the importance of neural and glial dysfunction in the pathophysiologic progress of hyperglycemiainduced retinopathy and neurodegeneration as well as glial modifications also occur in the STZ diabetic rodent model $[67,68]$. Fibrosis is an important pathological feature of early-stage (capillary basement membrane thickening) and late-stage (fibrosis-induced contraction and retinal detachment) DR. It has indeed been demonstrated that the major fibrogenic factor connective tissue growth factor (CTGF) is overexpressed in DR patients as well as in the STZinduced hyperglycemic model $[94,95]$.

Methodology: There are a plethora of different protocols with regard to STZ-induced hyperglycemia in the mouse and rat [53]. Rats are mostly injected intravenously or intraperitoneally with one high dose of STZ after overnight fasting [71,73,77,96-99], whereas mice often receive multiple lower STZ doses on consecutive days after only a few hours of fasting or even no fasting period [100-103]. Mouse STZ studies are almost exclusively performed in $\mathrm{C} 57 \mathrm{Bl} / 6$ mice, while various rat breeding lines have been used in rat STZ experiments: e.g. Brown Norway, Wistar and Sprague Dawley. It is important to note that the DR-associated pathogenic modifications can vary depending on the used rat strain [53].

Indeed, Zhang et al., have elegantly demonstrated that Brown Norway rats exhibit more sustained and pronounced retinal leakage patterns compared to non-pigmented Sprague Dawley rats [71]. These findings can potentially explain the different time-windows that are used to perform the retinal vascular leakage read-out in the diabetic rat STZ model. Some research groups already assess the permeability level in the diabetic rat eyes approximately 2 weeks after STZ injection $[70,73,75,104]$, while most groups determine the increased leakage level after a longer period of hyperglycemia even up to 6 months postinjection $[61,69,96,105,106]$.

Comparable to other vascular leakage models, e.g. rat VEGFinduced retinal permeability model [71,107], the quantitative Evans Blue method is also often applied in the diabetic rodent STZ model $[71,98,104]$. Several studies have demonstrated that perfusion with FITC-conjugated albumin or dextran in STZ-induced diabetic animals is a reliable technique to assess retinal permeability quantitatively $[69,106,108,109]$ (Figure 1).
Various other techniques have been optimized such as fundus fluorescein angiography [110], histology and immunohistochemistry for the tight junction components zona occludens 1 (ZO-1 = tight junction protein 1 or TJP1), claudin-5 and occludin [111,112]; quantitative fluorophotometry in rat eye [113-116] and OCT thickness measurements $[116,117]$. Thus, most of the techniques are focused on determining the vascular complications in the hyperglycemic eyes of STZ mice and rats.
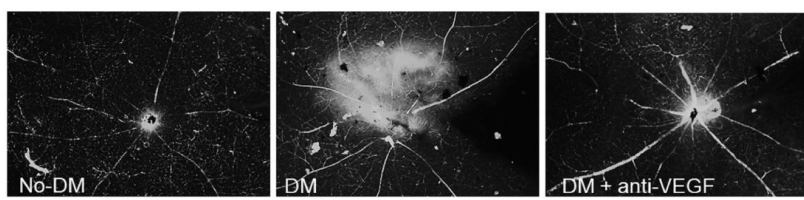

Figure 1: Therapeutic inhibition of vascular leakage in mouse STZ model. Ocular administration of a VEGF inhibitor decreases hyperfluorescent area in fluorescein-BSA perfused retinal flatmounts of STZ-induced diabetic mice.

However, several research groups have successfully implemented optokinetics and/or ERG to assess modifications in visual functionality instead of vascular permeability dysfunctions $[53,118]$. This illustrates that the STZ rodent model can be used for validation of potential new DR drug candidates that can prevent diabetic vision loss and/or improve vision in DR patients already exhibiting visual deficits.

Transgenic Akimba mouse model: The pathogenic molecular and cellular mechanisms of DME and DR remain largely elusive, mainly due to lack of reliable diabetic animal models that display all the key pathogenic DR-related characteristics. For this reason, the research group of Prof. Racokzy recently generated the Akimba (Ins2 ${ }^{\text {AkitaVEGF }}$ ${ }^{+/-}$) mouse model by crossing the diabetic Akita mouse line (Ins2 ${ }^{\text {Akita }}$ ) with the Kimba mouse line $\left(\mathrm{VEGF}^{+/-}\right)$[119]. The Akita mouse is a naturally occurring insulin-dependent type 1 diabetes model $[120,121]$. The heterozygous Akita male mice develop features similar to early pathophysiological changes of diabetic complications, but fail to exhibit the advanced stage vascular dysfunctions. The non-diabetic Kimba (trVEGF029) mouse model, in which photoreceptors transiently overexpress hVEGF, is characterized by several early and advanced DR-associated vascular changes such as vascular permeability, capillary non-perfusion, microaneurysms and retinal neovascularization [119,122-127]. It has been reported that the combination of high blood glucose levels and VEGF overexpression exacerbates the vascular complications in the Akimba mouse eye $[119,127]$.

Biochemical and molecular pathways: The Akimba model is one of the most optimal animal models to study the pathogenesis of DR given that several key DR-related dysfunctions can be investigated in this diabetic mouse model. Most importantly, the Akimba mouse exhibits distinct (micro)vascular complications comparable to the clinical DR and DME context.

The combination of hyperglycemia and VEGF overexpression in the Akimba mice results in the presence of microaneurysms, tortuous vessels, venous beading, vessel dilation and in later stages also capillary non-perfusion. In addition, these mice exhibit a distinct increase in vascular leakage and edema (Figure 2) and this is more pronounced in 
young (approximately 8 weeks old) compared to old (approximately 25-26 weeks old) Akimba mice $[119,128]$.

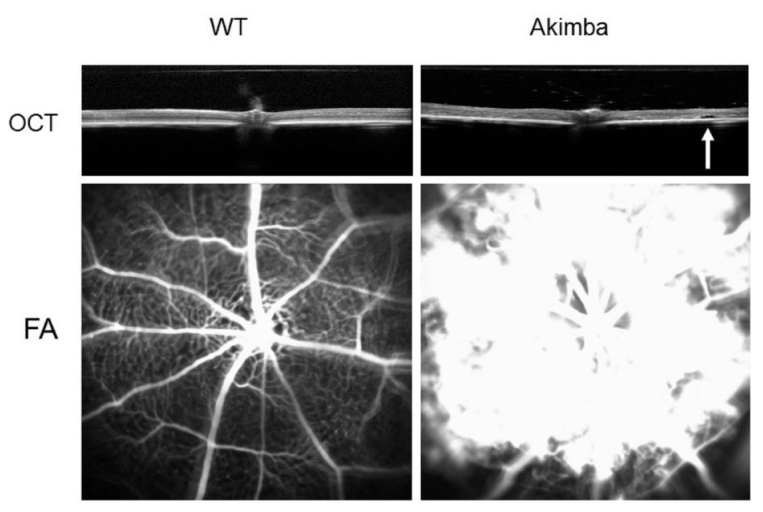

Figure 2: Retinal imaging in the Akimba mouse model by means of SD-OCT and FA analysis. Spectral domain optical coherence tomography (SD-OCT) analysis in the wild type (WT) mouse eye (top left) and the Akimba mouse eye (top right) demonstrates that the retinal layers are affected in the diabetic Akimba eye. Interestingly, edema is observed in the retina of the Akimba mouse (arrow), which indicates that the Akimba mouse exhibits increased retinal permeability. FA analysis in the corresponding WT mouse eye (bottom left) as well as the Akimba mouse eye (bottom right) reveals distinct modifications in the retinal vasculature. Vascular leakage is clearly present in the retina of the Akimba mouse as bright patchy spots.

The increased vascular leakage in the diabetic Akimba mice is directly associated to pericyte loss and decreased expression of tight junction components such as claudin-5 and occludin (not ZO-1), implying a disruption of the BRB [127]. In contrast, the non-diabetic Kimba mice display no alteration in BRB protein levels nor pericyte coverage; although FA analysis also revealed clear vascular leakage in the retinas of VEGF-overexpressing Kimba mice.

Retinal neovascularization is extensively observed in the Akimba and Kimba mouse models $[119,122,125]$. Comparable to DR patients, neovascularization in both mouse models is observed in the retina and not in the choroid $[119,126]$. Preretinal neovascularization, which is a well-known human characteristic of proliferative DR [129], is not present in the Akimba or the Kimba model, given that the formation of new blood vessels is directed toward the VEGF-overexpressing photoreceptors in the outer retina [119].

Thorough characterization studies allowed the Rackozy research group to determine that angiogenesis phenomena are more pronounced in Akimba mice in comparison to Kimba mice. Overall, the hyperglycemic conditions in the Akimba mice render the retinal vasculature more susceptible to the risks of VEGF overexpression, which results in more severe microvascular dysfunctions compared to the Kimba mouse $[119,127]$. Intravitreal injection of a VEGF inhibitor suppresses vascular leakage in the Akimba mice (unpublished data, ThromboGenics) (Figure 3).

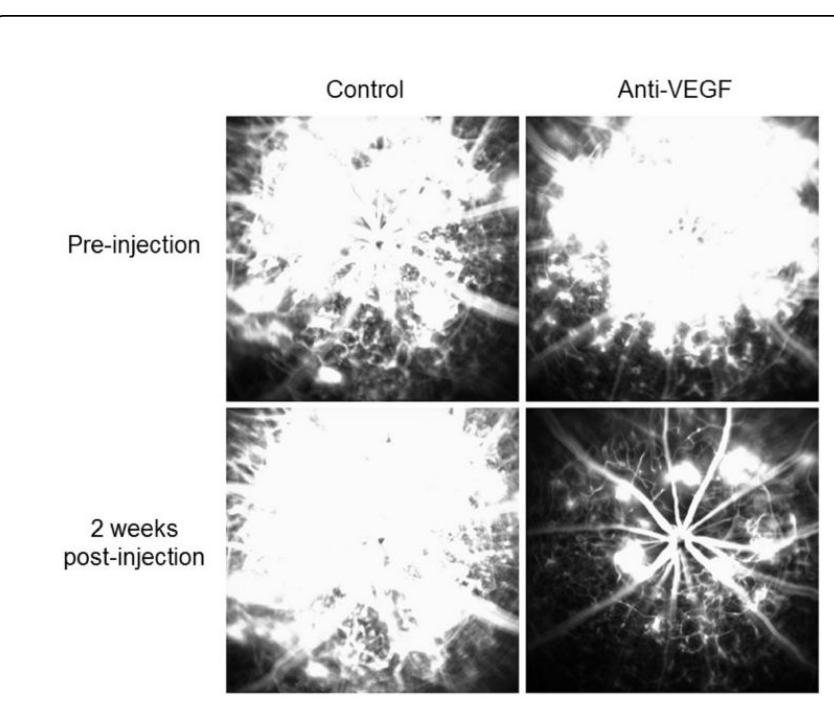

Figure 3: Therapeutic inhibition of vascular leakage in the diabetic Akimba mouse model. The retinal permeability level can be inhibited by intravitreal injection of a VEGF inhibitor. Baseline FA analysis before treatment reveals the clear presence of vascular leakage in the retina of the Akimba mouse (top panels). Two weeks after intravitreal injection of a VEGF inhibitor the retinal permeability level is significantly decreased (bottom right), while vehicle-treated control eyes displayed no inhibition in vascular leakage level (bottom left).

In addition to the vascular modifications, other DR-associated pathways can be investigated as well in the hyperglycemic Akimba mouse model. For instance, inflammation was also observed in the Akimba mouse. Staining for major histocompatibility complex class IIpositive immune cells was increased in the entire retina and this could be associated with the breakdown of the BRB [119]. Rahman reported the aberrant presence of monocytes and macrophages throughout the retinas of Akimba and Kimba mice $[122,128]$. An increase in glial fibrillary acidic protein (GFAP) staining was also noticed in the diabetic Akimba eyes, which is indicative for retinal gliosis [128]. The aforementioned vascular and inflammatory pathogenic pathways appear to be interlinked with neurodegeneration processes. In the Akimba mouse retinal thinning was observed and this was mainly associated to extensive degeneration of the photoreceptor layer and loss of retinal ganglion cells $[119,124,128]$. Finally, fibrosis pathogenic pathways can also be studied in the Akimba mouse model given that a substantial amount of fibrotic tissue was observed in the retinas of the majority of the old Akimba mice [119].

As the diabetic Akimba mouse model has only recently been engineered [119], not much is investigated yet with regard to the essential molecular mechanisms for the retinopathy-linked pathways in this diabetic eye model. Nevertheless, it has already been reported that endothelin 2 (Edn2), Edn3 and the endothelin receptor B (Ednrb) were upregulated in Akimba mice. Edn2 is a known chemo-attractive molecule for macrophages and protects against hypoxia conditions, while Edn3 is involved in axonal outgrowth and guidance in the central nervous system, but the exact role for the upregulation of the endothelin pathway in the diabetic eye has not been scrutinized yet [128]. Moreover, Wisniewska-Kruk et al., demonstrated that 
plasmalemma vesicle associated protein (Plvap) gene expression is augmented in the Akimba eye [127]. Plvap is an endothelial-specific protein, which is only expressed in the disrupted BRB under pathological conditions such as DR.

Methodology: It has been shown that the non-invasive FA technique can be used to monitor the retinal permeability level in the Akimba mouse eye and vascular leakage is clearly visible as bright patchy spots $[119,127]$. Besides FA, SD-OCT can also be used to assess the retinal permeability as well as morphology. Comparable to the clinical DR situation, edema can be discerned in the OCT cross section images of the Akimba mouse model, signifying the manifestation of retinal vascular leakage. OCT analysis furthermore demonstrated that the neuronal layers of the retina are noticeably thinner, which implies the presence of neuronal degeneration in the hyperglycemic Akimba eye [119]. As a consequence, assessment of retinal permeability via retinal thickness measurements is hampered, given the opposed effect of degeneration-related thinning and leakage-induced thickening of the retinal layers $[116,117]$. In addition, retinal permeability can be investigated by perfusing the mouse eyes with FITC-conjugated dextran or bovine serum albumin (BSA), which leaks out of the damaged retinal blood vessels of the diabetic eye. A significant increase of permeability can be observed in the retina of diabetic Akimba mice compared to normal wild-type animals (unpublished data ThromboGenics, Figure 2). Other techniques have been utilized to investigate the neovascularization processes in the retina of the Akimba mouse. By means of histology and immunohistochemistry staining for the endothelial markers CD-31 and isolectin B4, the growth of new blood vessels towards the outer retina has been revealed $[119,127]$.

The Akimba mouse could be an important diabetic animal model to improve our insight in the complex processes of DR pathogenesis. Given the pronounced induction window of retinal vascular leakage in comparison with the normal mouse eye, this diabetic eye model appears to be an excellent model for inhibition studies. On the other hand, it has to be taken into account that these robust vascular dysfunctions in the retina of the Akimba mouse could indicate that only strong inhibitory compounds will have the potency to ameliorate the retinopathy. In summary, further studies are necessary to elucidate whether the Akimba mouse model is a reliable tool for testing the in vivo efficacy of new drug candidates directed against retinal permeability and neovascularization.

\section{Surrogate ocular models}

Mouse model of choroidal neovascularization: $\mathrm{CNV}$ is the hallmark of neovascular age-related macular degeneration (AMD). It is characterized by the abnormal growth of new vessels originating from the choroid under the retinal pigment epithelium (RPE) and/or into the subretinal space. The laser-induced CNV model is the standard animal model to evaluate new therapies for neovascular AMD and other neovascular diseases in the eye [54]. The model was applied to mice for the first time in 1998 by Tobe et al. and provided preclinical evidence of anti-VEGF therapy efficacy for ocular neovascular diseases such as wet AMD and DR $[28,130,131]$.

Biochemical and molecular pathways: Key process in this model is growth of new blood vessels from the choroid into the subretinal space. Choroidal neovascularization is induced by increased levels of proangiogenic factors at the place of disruption between the RPE and Bruch's membrane. A key pro-angiogenic factor expressed by the RPE/ choroid complex, but also macrophages involved in the $\mathrm{CNV}$ pathogenesis, is VEGF. Its expression peaks at 5-7 days after laser photocoagulation. Anti-angiogenic potency of aflibercept, an antagonist of VEGF and placental growth factor (PIGF), has been demonstrated in the mouse $\mathrm{CNV}$ model and has resulted in clinical development [28,131] (Figure 4). Besides VEGF therapy, new blood vessel formation and/or vascular leakage could be reduced by inhibition of expression or activity of mediators involved in other angiogenesis related signaling pathways such as PlGF, angiopoietin-1, fibroblast growth factor (FGF) receptors FGFR1 and 2, HIF-1 $\alpha$, apelin or Rho kinase (ROCK) [132-136]. Studies in the mouse CNV model have also identified an anti-angiogenic role for bone morphogenetic protein-4 (BMP-4) by inhibition of MMP-9 [137]. It is worth to mention that mouse CNV can also be the result of a decrease of antiangiogenic factors. Indeed, mouse $\mathrm{CNV}$ can be regulated by the release of anti-angiogenic proteolytic fragments from basement membranes. Mice lacking endostatin, a proteolytic fragment of collagen XVIII, demonstrated increased CNV [138].

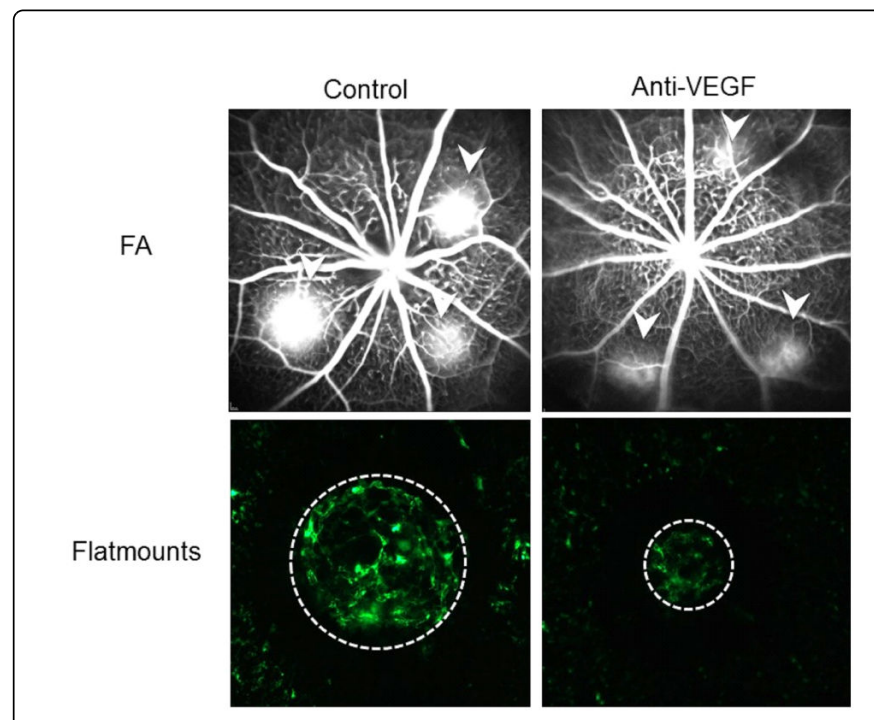

Figure 4: Therapeutic inhibition of vascular leakage and neovascularization in mouse $\mathrm{CNV}$ model.

Laser photocoagulation basically initiates a wound-healing process that relies on inflammation by macrophage accumulation. High expression levels of pro-inflammatory cytokines/chemokines including MCP-1, IL-6 and TNF- $\alpha$ are observed during the first 3-5 days after laser photocoagulation. Neutralization of their activity by targeting the ligand or receptor was able to reduce macrophage infiltration as well as the size of laser-induced CNV [139-142]. More downstream of the inflammation pathway, blocking the nuclear factor $\kappa B(\mathrm{NF}-\kappa \mathrm{B})$ activator inhibitor of nuclear factor $\kappa B$ kinase 2 (IKK-2) reduced $C N V$ [143]. Also adhesion molecule ICAM-1 plays a relevant role in CNV since neovascularization is reduced in ICAM-1 knockout $(\mathrm{KO})$ mice [144]. Macrophages in CNV express Notch receptors of delta like ligand 4 (DLL4) and receptor activation leads to CNV reduction [145]. Macrophages also express the membrane glycoprotein CD200R and stimulation of this receptor by an agonistic antibody reduces expression of pro-angiogenic genes and inhibits CNV [146]. Recently, the role of inflammation in the mouse CNV has been confirmed by the efficacy of the glucocorticoid triamcinolone acetonide that has antiinflammatory effects and is used in clinical practice to treat ocular 
pathologies associated with vascular leakage and ocular neovascularization [147].

Apoptosis might be one of the triggers of the choroidal inflammation and subsequent angiogenesis in this model. Inhibiting apoptosis by a pan-caspase inhibitor in the first several hours after laser treatment suppressed neovascularization. Also inhibition of total c-Jun N-terminal kinase (JNK), that is activated under oxidative stress, and plays a key role in apoptosis, decreased CNV [148]. Oxidative stress, caused by accumulation of ROS, has been implicated in the development of laser-induced $\mathrm{CNV}$ as well. Indicative are the upregulation of 4-hydroxy-2-nonenal (HNE)-modified protein, a marker of oxidative stress, and the reducing effect of the anti-oxidants $\mathrm{N}$-acetyl cysteine and glutathione peroxidase $4(\mathrm{GPx} 4)$ on $\mathrm{CNV}$ development $[149,150]$.

At late stage, $\mathrm{CNV}$ lesions evolve into fibrotic scars as a consequence of the wound healing process. The mouse CNV model has already been used to investigate drug efficacy on choroidal fibrosis. So, blockage of the receptor of the pro-inflammatory mediator platelet-activating factor (PAF), administering a Rho kinase inhibitor or inhibition of lysyl oxidase (LOX) resulted in reduced fibrosis formation in this model $[135,151,152]$. Also genetic ablation of periostin (POSTN), a secreted matricellular protein, enabled to suppress fibrosis formation in mouse CNV [153]. POSTN interacts directly with the extracellular matrices, including fibronectin, tenascin $\mathrm{c}$ and collagen type I and interestingly, its expression is enhanced in the vitreous and fibrovascular membranes (FVMs) of PDR patients and proliferative vitreoretinopathy.

Methodology: Briefly, the model relies on laser burning of Bruch's membrane using a green Argon laser or Krypton laser. The wound healing reaction that is generated leads to inflammation and finally, the growth of new blood vessels and formation of fibrotic scars into the subretinal space. The angiogenesis response is most often examined by fluorescence microscopy after perfusion of the eyes with fluorescein labeled dextran and flat-mounting choroid tissue [154]. In wild-type $\mathrm{C} 57 \mathrm{Bl} / 6$ mice, the mouse strain which is most often utilized for $\mathrm{CNV}$, this acute neovascular response typically peaks 7 days after laser injury and decreases thereafter due to spontaneous recovery of the RPE [154-156]. Other factors affecting CNV activity are age, sex, treated positions of laser spots and even the origin of the animals [156,157]. The new blood vessels formed in the lesions are leaky as demonstrated by FA $[155,158-161]$. Leakage visualized by FA is most frequently graded by an established scheme based on the spatial and temporal evolution of fluorescein leakage [162]. Indocyanine green angiography (ICGA) and SD-OCT are other non-invasive methods which are used in vivo to visualize angiogenesis and morphological changes of the retina respectively $[155,158,163,164]$. Recently, SD-OCT was also applied to determine treatment efficacy on CNV lesion size [160]. Additionally, it allowed to determine subretinal fluid detection and was suggested as marker for CNV activity [163]. However, no clear relation could be found between FA-detected hotspots and retinal edema detection by SD-OCT [155].

Mouse model of oxygen-induced retinopathy: Hypoxia in the retina may occur as a result of vascular disruption caused by various pathologies, such as hyperglycemia in diabetes or developmental delays in retinopathy of prematurity (ROP). In the eye, hypoxic conditions trigger a vascular response, which can lead to the formation of neovascular sprouts from the remaining capillaries and veins $[165,166]$. Arteries do not develop sprouts, but become tortuous instead. The pathologic neovessels leave the highly organized, layered structure of the retina and grow into the normally avascular vitreous cavity to form preretinal neovascular tufts, which are a hallmark of ischemic retinopathies and indeed resemble the pathologic neovascularization seen in human ROP or PDR [167,168] (Figure 5). This is a major vision-threatening complication in many ischemic retinopathies because the abnormal vessels leak, which results in edema and exert tractional forces, causing in worst-case scenarios retinal detachment [169].

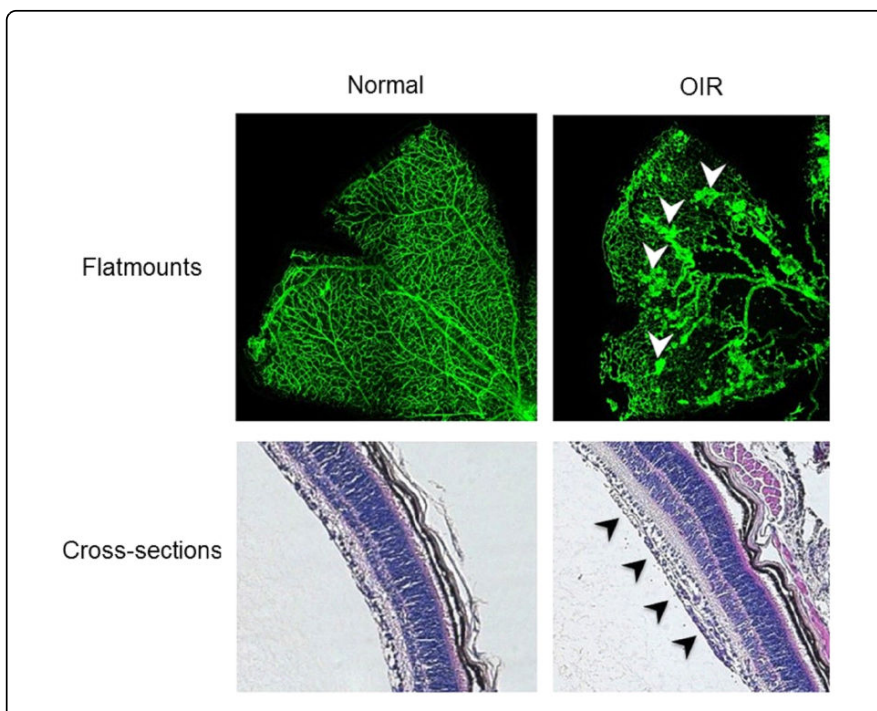

Figure 5: Preretinal neovascularization in mouse OIR model.

Biochemical and molecular pathways: The mouse model of ROP is mainly characterized by the sudden onset of hypoxia and the overexpression of hypoxia-inducible growth factors, such as HIF-1a. It is indeed known that HIF-1a expression is induced in murine retina during normal development, downregulated during hyperoxia and upregulated upon return to normoxic conditions (relative hypoxia) [170]. Different studies have already shown that the decrease of HIF-1 $\alpha$ activity and/or expression by mutations (e.g. HIF $(\mathrm{kd} / \mathrm{kd})$ knock-out mice [171] and RTP801 (HIF-1 $\alpha$ responsive gene) knockout mice [172] or drugs (e.g. deguelin [173]) reduces the oxygeninduced neovascularization. This reduction in neovascularization can be explained by the fact that the expression pattern of HIF-1a is temporally and spatially correlated with different pro-angiogenic factors. One of the most important pro-angiogenic molecules that has been intensively studied in the context of neovascularization is VEGF. Indeed, VEGF expression is known to be upregulated approximately 6-12 hours after returning the neonatal mice to hypoxic conditions, leading to the formation of new blood vessels [174]. VEGF is secreted by the supporting astrocytes that are closely associated with endothelial cells $[175,176]$. Moreover, Ishihama et al. showed that VEGF-R2 and neuropilin-1 (NRP-1, co-receptor of VEGF-R2) are mainly expressed on neovascular vessels in the ROP mouse model, suggesting that the interaction between VEGF, VEGF-R2 and NRP-1 plays an important role in pathological retinal neovascularization [177]. It has already been described in literature that the retinal neovascularization in the ROP mouse model can be reduced by the application of VEGF inhibitors, such as bevacizumab [135,178-180] and aflibercept [181], which has resulted in the use of bevacizumab as gold standard in clinical practice [182]. Other commonly used drugs in clinical practice for the treatment of ocular neovascularization and 
inflammation, such as dexamethasone [183] and triamcinolone acetonide [184] have shown to be effective in the ROP mouse model as well. Of note, evidence on the effect of inflammatory response in the ROP model is lacking in literature.

The link between VEGF and IGF-1 in the process of angiogenesis in the mouse ROP model is well described and is known to be regulated by the activation of p44/42 MAPK signaling pathway [185,186]. IGF-1 appears to play a permissive role in VEGF-mediated new vessel growth. In contrast, Hellstrom et al. showed that IGF-1 deficient mice reduced the oxygen induced neovascularization, despite the presence of VEGF [187]. The role of integrin and cyclooxygenase (COX) as potential target to treat retinal angiogenesis has also been investigated. Antagonists of $\alpha_{\mathrm{V}}$-type integrins $[188,189]$ and COX-inhibitors $[190,191]$ have shown to be effective in attenuating hypoxia-induced retinal angiogenesis. Moreover, a very recent study demonstrated that interaction between VEGF and integrins may be regulated by cyclin 1 (CCN-1), an extracellular matrix (ECM) signaling molecule, via the PI3K/Akt pathway [192].

Different studies also demonstrated that new blood vessel formation can also be reduced by inhibition of expression or activity of mediators involved in other angiogenesis related signaling pathways such as Epo [193], NO [194,195], apelin [196], adenosine [197,198] and fatty acid binding protein 4 (FABP4) [199]. Importantly, recent studies have demonstrated that angiogenesis can be controlled by the adrenergic system through its regulation of pro-angiogenic factors [200,201]. Two small pilot, randomized controlled trials investigating oral proponalol ( $\beta$-adrenergic inhibitor) in preterm infants with ROP, have shown a non-significant reduction of ROP requiring intervention by laser treatment or bevacizumab injection of similar magnitude [202,203]. However, large interventional studies are needed to determine the clinical benefit-risk ratio, since the administration of $\beta$-AR inhibitors might be associated with serious adverse effects (e.g. hypotension, bradycardia).

Besides the process of angiogenesis, breakdown of the BRB and vascular leakage can also be observed in the ROP mouse model. Different studies of the group of Vinores S. showed that inhibition of VEGF-R1 by the monoclonal antibody MF1 was more effective in reducing the ischemia induced BRB-breakdown than inhibition of VEGF-R2 (using DC101) [204]. The deficiency of prolyl hydroxylases (PHDs), oxygen sensors that stabilize HIFs to induce proinflammatory, vasopermeability and pro-apoptotic factors, is also known to be correlated with reduced vascular leakage and pathological neovascularization [205]. Systemic administration of retinoic acid (RA) [206] and brimonidine [207] are also known to attenuate the process of leakage in the mouse ROP model. Moreover, different studies show that angiopoietin-1 supplementation can rescue vascular retinopathies by simultaneously promoting healthy vascular network formation and inhibiting subsequent abnormal angiogenesis, vascular leakage, and neuronal dysfunction in the retinas of the ROP mouse model $[208,209]$, making angiopoietin- 1 an attractive target.

Finally, the mouse model of ROP shows glial and neuronal damage and retinal apoptosis associated with the vascular disease [210,211]. Indeed, the group of Sennlaub showed for the first time that retinal apoptosis was present in the mouse model of ROP by demonstrating that inducible NOS (iNOS) is playing a crucial role not only in retinal neovascular disease but also in retinal degeneration [211]. Later, various studies confirmed neuronal apoptosis and/or retinal degeneration in the ROP retina [172,212-214]. The cellular mechanisms causing this neurodegeneration are still unknown.
However, a lot of research has been performed to investigate the role of arginase 2 , an ureahydrolase enzyme that converts arginine, since it is known that a deficit in L-arginine may be involved in ROP pathology. Deletion of arginase 2 and the administration of the arginase 2 inhibitors, indeed significantly improved neuronal survival in the mouse ROP model, through the regulation of the polyamine metabolism [215-217]. It is also known that apoptosis in the retina was reduced in PHD1-depleted mice [205]. Finally, a very recent paper showed that genetic deletion of aldose reductase, the rate-limiting enzyme in the polyol pathway, not only reduces pathological angiogenesis, but also preserved retinal functions in ROP [214].

Methodology: ROP can be induced by exposing C57Bl/6 mice to $75 \%$ oxygen from postnatal day 7 to day 12 and thereafter returned to normoxic conditions for 5 days. At day 17, the process of neovascularization can be investigated in retinal tissue by $\mathrm{H} \& \mathrm{E}$ of eye cross sections or isolectin-B4 staining on retinal flatmounts $[218,219]$ (Figure 5). Quantification is based on counting nuclei in the endothelial cell compartment on the vitreal side of the inner limiting membrane of the retinal sections (H\&E staining) [167], or by automated image analysis of the isolectin B4 stained retinal flatmounts $[181,220,221]$. The isolectin B4 staining allows assessment of several morphological changes of the vasculature in the retinal flatmount associated with a proliferative endothelial cell response.

Rodent VEGF-induced retinal permeability: It has been repeatedly reported that intravitreal injection of VEGF can result in BRB breakdown and retinal neovascularization in different species [113,222-227]. Besides VEGF, other compounds have been injected into the eye to induce retinal permeability, such as betacellulin [100,101], PKal [115,116], azurocidin [98] and PlGF [228]. Nonetheless, VEGF is unmistakably the most frequently used and best studied compound that can potently induce vascular leakage and angiogenesis in the eye after intravitreal administration.

Biochemical and molecular pathways: The VEGF-induced retinal permeability model is especially suitable to investigate vascular complications that are also implicated in DR pathogenesis. Indeed, intravitreal injection of pathophysiological concentrations of VEGF can induce DR-like vascular dysfunctions such as vascular tortuosity, micro-aneurysms and vascular leakage, and this in different species: mice $[99,100,107]$, rats $[96,98,229]$, rabbits [230] and monkeys [226,231,232]. In addition, capillary non-perfusion (rat [229,232]; rabbit [230]; monkey [226,231,232]) and retinal neovascularization (rabbit [230], monkey [226,227,231]) have also been described after intra-ocular administration of VEGF.

The underlying cellular and molecular mechanisms of VEGFinduced vascular dysfunctions remain largely elusive. In 1997, however, Aiello et al., provided proof that activation of the PKC pathway is involved [113]. Rat studies with an intravitreally or orally administered PKC $\beta$-isoform-selective inhibitor indicated that the effect of VEGF on vascular permeability in the rat eye appears to be mediated predominantly by $\mathrm{PKC} \beta$.

Several more recent studies have pointed out that inflammatory pathways are implicated as well in VEGF-induced retinal permeability. Retinal upregulation of ICAM-1 expression was found after VEGF injection in the mouse eye [233] and rat eye [229]. Subsequently, intravitreal injection of VEGF can lead to adhesion of leukocytes to ICAM-1, implicating that the VEGF-induced vascular changes are, in part, mediated by leukostasis $[96,229]$. It is indeed described that vascular leakage in the retina can be induced by leukostasis-dependent 
breakdown of the BRB [96] and that adhered leukocytes can obstruct blood flow, causing capillary non-perfusion in the rat eye [232]. Interestingly, it has been reported that anti-inflammatory corticosteroids such as triamcinolone and dexamethasone can robustly inhibit retinal permeability in a rabbit VEGF-induced vascular leakage model [234].

Methodology: Intravitreal VEGF administration increases retinal vascular permeability in different species ranging from mouse, rat to rabbit and monkey. In most of the cases recombinant human VEGF165 (hVEGF165) is injected intravitreally [96,100,107,113,229,230,234], but other groups also use recombinant mouse VEGF164 (mVEGF164) to induce vascular leakage in the mouse or rat eye $[98,99]$. Depending on the species eye size different doses of VEGF are administered, but surprisingly the VEGF concentration injected in rodent eyes can already vary tremendously; for instance in the rat, doses ranging from $0.02 \mathrm{ng}$ to $250 \mathrm{ng}$ VEGF are described in literature [98-100,107,113,229].

The Evans Blue read-out technique is the golden standard to analyze vascular leakage in general and this method is also applied for the rat VEGF-induced retinal permeability model $[71,107]$. Several variants on this method have been implemented as well. For example, as an alternative to Evans Blue dye, Miyamoto et al. injected iodized BSA in Long Evans rats to assess the BRB leakage [229]. And FITC-conjugated albumin or dextran perfusion is often carried out as well and subsequently the perfused eyes are processed to retinal flat-mount in most cases performed $[107,113]$.

Furthermore, a number of research groups used the non-invasive fluorophotometry technique to quantify vascular leakage in the eye after intravitreal injection of VEGF. Fluorophotometry is mostly only implemented in the clinical context or for mammals with a more or less human-like eye size, such as the rabbit [234]. Only few quantitative fluorophotometry studies have been performed in the considerable smaller rat eye of non-pigmented Sprague Dawley rats $[113,114]$ and pigmented Brown Norway rats (unpublished data ThromboGenics data). Finally, the qualitative FA read-out has also been implemented in the rabbit and monkey VEGF-induced models to investigate retinal permeability and angiogenesis [226,230] and SD-OCT thickness measurements can also be implemented (unpublished data ThromboGenics).

\section{Surrogate non-ocular models}

Rodent skin permeability assay: One of the first in vivo models used to examine vascular permeability is the Miles assay [235]. This method is based on intravenous injection of Evans Blue in mice and subsequent visualization of its diffusion into interstitial spaces. Evans Blue binds albumin that, under normal conditions, remains restricted within blood vessels. In pathological conditions, increase of vascular permeability allows extravasation of Evans Blue in tissues. VEGF is one of the most potent inducers of vascular permeability and intradermal injection of VEGF into the back or ear skin of rodents became a popular model that allowed leakage assessment by simple visualization [235-237]. Besides VEGF, also intradermal injections of plateletactivating factor, histamine, bradykinin, prostanoid PGE2 and galectin-1 were demonstrated to increase skin permeability [238-240].

Biochemical and molecular pathways: Intradermal injected VEGF was suggested to directly enhance permeability of established vessels since other angiogenic growth factors as PlGF, acidic and basic FGF, platelet-derived growth factor (PDGF)-BB, transforming growth factor $\beta$ (TGF- $\beta$ ), scatter factor, and granylocyte-macrophage-colony factor failed to increase vascular permeabililty [238]. Remarkably, VEGFinduced permeability could be reduced by administration of NOS inhibitors and COX-inhibitor indomethacin without affecting inflammatory cells.

Noteworthy, the effect of anti-inflammatory agents on vascular permeability can be examined in variants of the Miles assay, wherein an inflammatory response is induced by topical application of the inflammatory mediator allyl isothiocyanate, also known as mustard oil, or an oxazolone solution [241,242]. Vasostatin, an endothelial cell inhibitory factor, was able to reduce oxazolone-induced inflammation and vascular permeability [241]. An antagonist of the tachykinine NK1 receptor was able to downsize mustard oil induced edema while antagonists of histamine and 5-hydroxytryptamine (5-HT) receptors failed [242].

Methodology: Evans Blue is injected intravenously followed by intradermal injection of VEGF in the back skin of mice, rats or guinea pigs. Skin permeability can be quantified by measurement of the intensity and area of the blue color changes or by dye extraction from the tissue and colorimetric measurement of the dye incorporated per tissue weight. More recent imaging methods such as diffuse reflectance spectroscopy, intravital microscopy and laser Doppler blood flow imaging allowed to evaluate in vivo leakage, vessel dilation and blood flow into the skin $[239,243]$.

Rat paw edema model: Carrageenan is a family of polysaccharides made of repeating galactose-related monomers. The lambda carrageenan type does not gel strongly at room temperature and is commonly used to induce an acute and reproducible in vivo inflammatory response. When lambda carrageenan is injected in the rat paw, the paw gets inflamed and starts swelling. This model of carrageenan-induced edema formation is widely used to determine the activity of anti-inflammatory compounds.

Biochemical and molecular pathways: The carrageenan-induced rat paw model involves several mediators and the model has been frequently assessed to study anti-inflammatory effects of less specific natural products. However, studies using more targeted agents enabled to demonstrate the role of pathway-specific mediators. Three phases in which various mediators operate in sequence have been postulated for edema formation in this model [244]. In the early hyperemia (0-2 h), there is a release of histamine and 5-hydroxytryptamine. Antagonists and agonists of the histamine receptors $\mathrm{H} 2$ and $\mathrm{H} 3$ respectively were shown to inhibit edema in this model [245-247]. Also an agonist of the serotonin receptor $5-\mathrm{HT}_{7}$ exhibited anti-edema activity in this model [248]. A second phase is mediated by bradykinin. An antibody blocking PKal, an enzyme that cleaves high molecular weight kininogen to generate bradykinin, produced significant inhibition of edema in this model [249].

A third phase has been correlated with the accumulation of inducible COX-2 which catalyzes the conversion of arachidonic acid to inflammatory prostaglandins and thromboxane. Efficiency of several anti-inflammatory inhibitors targeting the arachidonic acid pathway as non-steroidal anti-inflammatory drugs (NSAIDs) have been assessed in the rat paw edema model. NSAIDs indomethacin and diclofenac are clinical examples inhibiting the COX enzymes COX-1 and COX-2 [250-252]. Also efficacy of more selective COX-2 specific inhibitors has been assessed in the rat paw edema model $[250,253]$. Rat paw edema can also be reduced by glucocorticoids [254,255], which inhibits the arachidonic acid pathway more upstream by blocking the activity of 
phospholipases. These enzymes release arachidonic acid from phospholipids.

Oxidative stress is also considered to play an important role in the model pathogenesis. Neutrophil infiltration contributes to the inflammatory response by the production of pro-inflammatory ROS, $\mathrm{NO}$ and oxygen-derived free radicals. NO is generated via the oxidation of the terminal guanidine nitrogen atom of $\mathrm{L}$-arginine by the enzyme, NOS. The early phase of rat paw edema is accompanied by an increase of constitutive NOS (cNOS) activity and the late phase by a marked increase in iNOS [256]. NOS inhibitors reduced NO production and edema in the carrageenan-induced rat paw edema model $[256,257]$. The generation of ROS in the rat paw edema model could be suppressed by Salbutamol, a $\beta 2$ adrenergic receptor agonist that also has anti-inflammatory effects [258].

Neutrophil accumulation also liberates multiple pro-inflammatory cytokines. TNF- $\alpha$ and IL- $1 \beta$ are major mediators in the carrageenaninduced inflammatory response. Most of the cytokines stimulate the cellular chemotaxis and serve to further increase tissue inflammation. Maprotiline, an anti-depressant agent treatment lead to decreased infiltration of leukocytes, reduced levels of TNF- $\alpha$ and IL-1 $\beta$ and inhibition of paw edema [259]. Similar, the anti-edema efficacy of clavulanic acid, an inhibitor of glutamate carboxypeptide II, or herbal extracts were related to deduced levels of IL-1 $\beta$, TNF- $\alpha$ or IL-6 [254,255,260].

Methodology: Lambda carrageenan solution is injected subcutaneously (SC) into the plantar region of the left hind foot. To quantify edema formation, paw swelling can be measured by manual dorso-ventral measurements using calipers, by a liquid column on a balance or by plethysmography [261,262]. The plethysmometer measures changes in paw volume by water displacement.

\section{Restrictions and advantages}

The use of rodents for ophthalmology research can be associated with some restrictions due to the difference in the anatomy of the eye as compared to the human situation. Indeed, due to the small rodent eye size, the large lens and inaccessibility of the vitreous, intravitreal injection and sampling of eye tissues can be difficult and require experience and training. Importantly, it is also known that rodents do not possess a macula, which makes it difficult to model exact macular diseases (e.g. age-related macular degeneration and diabetic macular edema) in mouse and rat $[263,264]$. Nonetheless, other mammalian eye models such as rabbit, cat, dog and pig also lack a central macula. Non-human primates are the only animals with a retinal structure closely resembling the human macula (for a review see [265]). The difference in ocular anatomy can also have an impact on drug delivery or pharmacokinetics. Indeed, the vitreous volume and viscosity differs between rodents and humans and in addition, a difference in vitreous diffusional path and time length affects drug distribution [266]. One should also bear in mind that most compounds are not cross-reactive to all species. Therefore, the correct animal for testing new drugs should be selected based on ocular anatomy, drug delivery, pharmacokinetics, cross-reactivity, and predicted mode of action. One should also remain cautious about extrapolating the findings of animal research to the care of human disease. Animal models are not precise replicas of the human pathology of DR and the pharmacokinetics and half-life of the therapeutic compounds might differ between rodents and human patients.
However, there are also advantages to use rodents in ophthalmology research. They are small, easily bred and relatively inexpensive to house. Also a variety of genetically altered rodents (knockout and transgenic models) is available to study eye diseases and a wide range of recombinant proteins and antibodies is readily available. Moreover, the rodent retina represents a well-characterized, readily accessible tissue for angiogenesis and leakage research. Due to the feasibility of imaging the retinal vasculature, detailed investigation of developmental and pathological vessel growth in vivo is possible. Also the formation and regression of blood vessels can be studied in a controlled setting, because of the postnatal development of the retinal vascular structure in rodents [168].

\section{Summary and Concluding Remarks}

In recent years, anti-VEGF agents and corticosteroids have emerged as new treatment for DR. However, other therapeutic alternatives are needed since a non-negligible part of treated patients do not demonstrate satisfactory levels of visual acuity improvement [26,27,29-32,48,267]. Additionally, these treatments target only advanced stages of the disease when vision has already been significantly affected. Furthermore, since these treatments are expensive and have a significant number of adverse effects, also new pharmacological therapies for the early stages of DR are needed.

Hypertension, hyperglycemia and hyperlipidemia are the established risk factors of DR which trigger multiple biochemical and molecular pathways. Increase in glucose metabolism pathways, augmented production of AGE and activation of the PKC pathway are generally considered as the major mechanisms contributing to DR. These pathways result ultimately in oxidative stress, inflammation, vascular occlusion, neurodegeneration and subsequent upregulation of growth factors and cytokines [4,268-271]. Despite many years of research it remains largely unknown which molecular and cellular pathways are the major drivers of DR pathogenesis and progression. A good understanding of the biochemical pathogenesis processes of DR is essential for the development of novel and more efficient interventional strategies against DR. Recently, proteomic studies have been carried out in DR patient samples to map the proteins that are differentially expressed and therefore could play a potential key role in DR pathogenesis (cfr. Introduction). Interestingly, several of these identified DR-regulated genes/proteins appear to be affected as well in the described DR animal models, implying that the clinical situation can at least in part be reflected in the animal models. For instance, the inflammatory mediators IL- 6 and MCP- 1 are increased in DR clinical vitreous samples and these two molecules are augmented as well in the $\mathrm{CNV}$ and STZ rodent models. And IL-6 also appeared to be upregulated in the rat paw edema model. In addition, the PKal level is significantly increased in clinical DME vitreous samples as well as in the rat paw edema and the rat STZ model. Furthermore, it is known that the IGF signaling pathway is affected in DR patients and this is mirrored in the STZ model as well as in the OIR model. This underlines the fact that diabetic as well as non-diabetic animal models that exhibit joint molecular pathways with human DR pathogenesis processes can be relevant for DR drug screening. Thus, new therapeutic approaches need to be found for DR that go beyond the current standards of DR care, and identifying appropriate (non)diabetic animal models could aid in developing innovative and effective treatments for the late as well the early stages of DR.

Dependent on environmental and genetic factors, the role of each pathway could differ in the DR patients. Predomination of different 
pathways and as consequence, the presence of different phenotypes can explain the variability in progression patterns in different diabetic individuals as well as the variability in therapeutic response $[34,36,272]$. Personalized therapy is a new trend aimed at achieving maximum therapeutic response in DR patients by a more tailored approach. The success of personalized therapies will not only depend on the identification of the different phenotypes and their relationship with the predominant pathways. Moreover, the availability and the strategic selection of representative animal models exhibiting these specific pathways will be essential in personalized DR drug profiling

This review describes a selection of surrogate, non-diabetic, and diabetic rodent models of pathogenic neovascularization, vascular permeability, inflammation and neurodegeneration and highlights the most relevant pathophysiological pathways and molecular mechanisms that these animal models have in common with DR patients. Table 1 presents a selected overview of DR-relevant pathways found to be involved in each model based on literature. Identification of the pathways might facilitate and improve the choice of an appropriate model used to evaluate the therapeutic potential of candidate drugs. Model choice can also be influenced by the goal of the preclinical study. The surrogate models are short-term models enabling higher throughput in vivo screening of potential drugs with limited costs, while the diabetic models take a relatively longer study duration because of the need to develop retinopathy, which in turn leads to a higher cost. Simplified, the selection of the most potent drug candidate might occur in a surrogate model and the efficacy as DR treatment can be assessed in a more translational model of DR. Main difference in the diabetic models is the presence of hyperglycemia, one of the main triggers of DR on the top of the pathway cascades. Although the presence of most of the DR relevant pathways confirms the translational value of diabetic rodent models (Table 1), additional studies in higher species (e.g. non-human primate) which are more closely related to human are recommended before proceeding with clinical activities.

In summary, this review might be considered as an onset to specify an in vivo screening strategy of novel drug candidates for DR in rodent models. A selection of surrogate and diabetic models is described and suggested as a tool for higher throughput screening activities or more translational drug efficacy studies, respectively. The most important biochemical and molecular pathways for DR pathogenesis are highlighted in each model to demonstrate model relevance for DR drug profiling. With the identification of the pathogenic pathways, researchers can select the most suitable models for drug screening. An appropriate selection of animal models might facilitate the development of more efficient novel personalized medicines, which are essential for future DR management.

\section{References}

1. Wu L, Fernandez-Loaiza P, Sauma J, Hernandez-Bogantes E, Masis M (2013) Classification of diabetic retinopathy and diabetic macular edema. World J Diabetes 4: 290-294.

2. Stewart MW (2015) The clinical utility of aflibercept for diabetic macular edema. Diabetes Metab Syndr Obes 8: 473-482.

3. Curtis TM, Gardiner TA, Stitt AW (2009) Microvascular lesions of diabetic retinopathy: clues towards understanding pathogenesis? Eye (Lond) 23: 1496-1508.

4. Simó R, Hernández C, European Consortium for the Early Treatment of Diabetic Retinopathy (EUROCONDOR) (2014) Neurodegeneration in the diabetic eye: new insights and therapeutic perspectives. Trends Endocrinol Metab 25: 23-33.
5. Deschler EK, Sun JK, Silva PS (2014) Side-effects and complications of laser treatment in diabetic retinal disease. Semin Ophthalmol 29: 290-300.

6. NACHOD GR (1951) ACTH and cortisone in ocular disease. J Am Med Womens Assoc 6: 453-455.

7. Bandello F, Preziosa C, Querques G, Lattanzio R (2014) Update of intravitreal steroids for the treatment of diabetic macular edema. Ophthalmic Res 52: 89-96.

8. Gillies MC, Lim LL, Campain A, Quin GJ, Salem W, et al. (2014) A randomized clinical trial of intravitreal bevacizumab versus intravitreal dexamethasone for diabetic macular edema: the BEVORDEX study. Ophthalmology 121: 2473-2481.

9. Ciulla TA, Harris A, McIntyre N, Jonescu-Cuypers C (2014) Treatment of diabetic macular edema with sustained-release glucocorticoids: intravitreal triamcinolone acetonide, dexamethasone implant, and fluocinolone acetonide implant. Expert Opin Pharmacother 15: 953-959.

10. Boyer DS, Yoon YH, Belfort R Jr, Bandello F, Maturi RK, et al. (2014) Three-year, randomized, sham-controlled trial of dexamethasone intravitreal implant in patients with diabetic macular edema. Ophthalmology 121: 1904-1914.

11. Bandello F, Cunha-Vaz J, Chong NV, Lang GE, Massin P, et al. (2012) New approaches for the treatment of diabetic macular oedema: recommendations by an expert panel. Eye (Lond) 26: 485-493.

12. Boyer DS, Hopkins JJ, Sorof J, Ehrlich JS (2013) Anti-vascular endothelial growth factor therapy for diabetic macular edema. Ther Adv Endocrinol Metab 4: 151-169.

13. Virgili G, Parravano M, Menchini F, Evans JR (2014) Anti-vascular endothelial growth factor for diabetic macular oedema. Cochrane. Database Syst Rev 10: CD007419.

14. Ferrara N, Damico L, Shams N, Lowman H, Kim R (2006) Development of ranibizumab, an anti-vascular endothelial growth factor antigen binding fragment, as therapy for neovascular age-related macular degeneration. Retina 26: 859-870.

15. Campochiaro PA (2007) Targeted pharmacotherapy of retinal diseases with ranibizumab. Drugs Today (Barc) 43: 529-537.

16. Economides AN, Carpenter LR, Rudge JS, Wong V, Koehler-Stec EM, et al. (2003) Cytokine traps: multi-component, high-affinity blockers of cytokine action. Nat Med 9: 47-52.

17. Holash J, Davis S, Papadopoulos N, Croll SD, Ho L, et al. (2002) VEGFTrap: a VEGF blocker with potent antitumor effects. Proc Natl Acad Sci USA 99: 11393-11398.

18. Ferrara N, Hillan KJ, Gerber HP, Novotny W (2004) Discovery and development of bevacizumab, an anti-VEGF antibody for treating cancer. Nat Rev Drug Discov 3: 391-400.

19. Presta LG, Chen H, O'Connor SJ, Chisholm V, Meng YG, et al. (1997) Humanization of an anti-vascular endothelial growth factor monoclonal antibody for the therapy of solid tumors and other disorders. Cancer Res 57: 4593-4599.

20. Stewart MW (2014) Anti-VEGF therapy for diabetic macular edema. Curr Diab Rep 14: 510.

21. Cheung N, Wong IY, Wong TY (2014) Ocular anti-VEGF therapy for diabetic retinopathy: overview of clinical efficacy and evolving applications. Diabetes Care 37: 900-905.

22. Truong A, Wong TY, Khachigian LM (2011) Emerging therapeutic approaches in the management of retinal angiogenesis and edema. J Mol Med (Berl) 89: 343-361.

23. Simó R, Sundstrom JM, Antonetti DA (2014) Ocular Anti-VEGF therapy for diabetic retinopathy: the role of VEGF in the pathogenesis of diabetic retinopathy. Diabetes Care 37: 893-899.

24. Wirostko B, Wong TY, Simó R (2008) Vascular endothelial growth factor and diabetic complications. Prog Retin Eye Res 27: 608-621.

25. Jeganathan VS, Wang JJ, Wong TY (2008) Ocular associations of diabetes other than diabetic retinopathy. Diabetes Care 31: 1905-1912. 
26. Nguyen QD, Brown DM, Marcus DM, Boyer DS, Patel S, et al. (2012) Ranibizumab for diabetic macular edema: results from 2 phase III randomized trials: RISE and RIDE. Ophthalmology 119: 789-801.

27. Korobelnik JF, Do DV, Schmidt-Erfurth U, Boyer DS, Holz FG, et al. (2014) Intravitreal aflibercept for diabetic macular edema. Ophthalmology 121: 2247-2254.

28. Heier JS, Brown DM, Chong V, Korobelnik JF, Kaiser PK, et al. (2012) Intravitreal aflibercept (VEGF trap-eye) in wet age-related macular degeneration. Ophthalmology 119: 2537-2548.

29. Do DV, Schmidt-Erfurth U, Gonzalez VH, Gordon CM, Tolentino M, et al. (2011) The DA VINCI Study: phase 2 primary results of VEGF TrapEye in patients with diabetic macular edema. Ophthalmology 118: 1819-1826.

30. Nguyen QD, Shah SM, Khwaja AA, Channa R, Hatef E, et al. (2010) Twoyear outcomes of the ranibizumab for edema of the mAcula in diabetes (READ-2) study. Ophthalmology 117: 2146-2151.

31. Massin P, Bandello F, Garweg JG, Hansen LL, Harding SP, et al. (2010) Safety and efficacy of ranibizumab in diabetic macular edema (RESOLVE Study): a 12-month, randomized, controlled, double-masked, multicenter phase II study. Diabetes Care 33: 2399-2405.

32. Mitchell P, Bandello F, Schmidt-Erfurth U, Lang GE, Massin P, et al. (2011) The RESTORE study: ranibizumab monotherapy or combined with laser versus laser monotherapy for diabetic macular edema. Ophthalmology 118: 615-625.

33. Campochiaro PA, Brown DM, Pearson A, Ciulla T, Boyer D, et al. (2011) Long-term benefit of sustained-delivery fluocinolone acetonide vitreous inserts for diabetic macular edema. Ophthalmology 118: 626-635.

34. Lobo CL, Bernardes RC, Figueira JP, de Abreu JR, Cunha-Vaz JG (2004) Three-year follow-up study of blood-retinal barrier and retinal thickness alterations in patients with type 2 diabetes mellitus and mild nonproliferative diabetic retinopathy. Arch Ophthalmol 122: 211-217.

35. Hove MN, Kristensen JK, Lauritzen T, Bek T (2006) The relationships between risk factors and the distribution of retinopathy lesions in type 2 diabetes. Acta Ophthalmol Scand 84: 619-623.

36. Nunes S, Ribeiro L, Lobo C, Cunha-Vaz J (2013) Three different phenotypes of mild nonproliferative diabetic retinopathy with different risks for development of clinically significant macular edema. Invest Ophthalmol Vis Sci 54: 4595-4604.

37. Gao BB, Chen X, Timothy N, Aiello LP, Feener EP (2008) Characterization of the vitreous proteome in diabetes without diabetic retinopathy and diabetes with proliferative diabetic retinopathy. J Proteome Res 7: 2516-2525.

38. Hernández C, García-Ramírez M, Colomé N, Corraliza L, García-Pascual L, et al. (2013) Identification of new pathogenic candidates for diabetic macular edema using fluorescence-based difference gel electrophoresis analysis. Diabetes Metab Res Rev 29: 499-506.

39. García-Ramírez M, Canals F, Hernández C, Colomé N, Ferrer C, et al. (2007) Proteomic analysis of human vitreous fluid by fluorescence-based difference gel electrophoresis (DIGE): a new strategy for identifying potential candidates in the pathogenesis of proliferative diabetic retinopathy. Diabetologia 50: 1294-1303.

40. Simó R, Higuera M, García-Ramírez M, Canals F, García-Arumí J, et al. (2008) Elevation of apolipoprotein A-I and apolipoprotein H levels in the vitreous fluid and overexpression in the retina of diabetic patients. Arch Ophthalmol 126: 1076-1081.

41. Simo R, Lecube A, Segura RM, Garcia AJ, Hernandez C (2002) Free insulin growth factor-I and vascular endothelial growth factor in the vitreous fluid of patients with proliferative diabetic retinopathy. Am J Ophthalmol 134: 376-382.

42. Kim T, Kim SJ, Kim K, Kang UB, Lee C, et al. (2007) Profiling of vitreous proteomes from proliferative diabetic retinopathy and nondiabetic patients. Proteomics 7: 4203-4215.

43. Ouchi M, West K, Crabb JW, Kinoshita S, Kamei M (2005) Proteomic analysis of vitreous from diabetic macular edema. Exp Eye Res 81: 176-182.
44. Funatsu H, Yamashita H, Ikeda T, Mimura T, Eguchi S, et al. (2003) Vitreous levels of interleukin-6 and vascular endothelial growth factor are related to diabetic macular edema. Ophthalmology 110: 1690-1696.

45. Hernández C, Segura RM, Fonollosa A, Carrasco E, Francisco G, et al. (2005) Interleukin-8, monocyte chemoattractant protein-1 and IL-10 in the vitreous fluid of patients with proliferative diabetic retinopathy. Diabet Med 22: 719-722.

46. Kita T, Clermont AC, Murugesan N, Zhou Q, Fujisawa K, et al. (2015) Plasma Kallikrein-Kinin System as a VEGF-Independent Mediator of Diabetic Macular Edema. Diabetes 64: 3588-3599.

47. He K, Lv W, Zhang Q, Wang Y, Tao L, et al. (2015) Gene set enrichment analysis of pathways and transcription factors associated with diabetic retinopathy using a microarray dataset. Int J Mol Med 36: 103-112.

48. Agarwal A, Soliman MK, Sepah YJ, Do DV, Nguyen QD (2014) Diabetic retinopathy: variations in patient therapeutic outcomes and pharmacogenomics. Pharmgenomics Pers Med 7: 399-409.

49. Simó R, Hernández C (2015) Novel approaches for treating diabetic retinopathy based on recent pathogenic evidence. Prog Retin Eye Res 48: $160-180$.

50. Cunha-Vaz J (2014) Phenotypes and biomarkers of diabetic retinopathy. Personalized medicine for diabetic retinopathy: the Weisenfeld award. Invest Ophthalmol Vis Sci 55: 5412-5419.

51. Robinson R, Barathi VA, Chaurasia SS, Wong TY, Kern TS (2012) Update on animal models of diabetic retinopathy: from molecular approaches to mice and higher mammals. Dis Model Mech 5: 444-456.

52. Jo DH, Cho CS, Kim JH, Jun HO, Kim JH (2013) Animal models of diabetic retinopathy: doors to investigate pathogenesis and potential therapeutics. J Biomed Sci 20: 38.

53. Lai AK, Lo AC (2013) Animal models of diabetic retinopathy: summary and comparison. J Diabetes Res 2013: 106594.

54. Grossniklaus HE, Kang SJ, Berglin L (2010) Animal models of choroidal and retinal neovascularization. Prog Retin Eye Res 29: 500-519.

55. Obrosova IG, Minchenko AG, Vasupuram R, White L, Abatan OI, et al. (2003) Aldose reductase inhibitor fidarestat prevents retinal oxidative stress and vascular endothelial growth factor overexpression in streptozotocin-diabetic rats. Diabetes 52: 864-871.

56. Pouliot M, Talbot S, Sénécal J, Dotigny F, Vaucher E, et al. (2012) Ocular application of the kinin B1 receptor antagonist LF22-0542 inhibits retinal inflammation and oxidative stress in streptozotocin-diabetic rats. PLoS One 7: e33864.

57. Joussen AM, Poulaki V, Qin W, Kirchhof B, Mitsiades N, et al. (2002) Retinal vascular endothelial growth factor induces intercellular adhesion molecule-1 and endothelial nitric oxide synthase expression and initiates early diabetic retinal leukocyte adhesion in vivo. Am J Pathol 160: 501-509.

58. Joussen AM, Doehmen S, Le ML, Koizumi K, Radetzky S, et al. (2009) TNF-alpha mediated apoptosis plays an important role in the development of early diabetic retinopathy and long-term histopathological alterations. Mol Vis 15: 1418-1428.

59. Zong H, Ward M, Madden A, Yong PH, Limb GA, et al. (2010) Hyperglycaemia-induced pro-inflammatory responses by retinal Müller glia are regulated by the receptor for advanced glycation end-products (RAGE). Diabetologia 53: 2656-2666.

60. Liu Y, Biarnés Costa M, Gerhardinger C (2012) IL-1 $\hat{I}^{2}$ is upregulated in the diabetic retina and retinal vessels: cell-specific effect of high glucose and IL-1 $\hat{I}^{2}$ autostimulation. PLoS One 7: e36949.

61. Shin JY, Sohn J, Park KH (2013) Chlorogenic acid decreases retinal vascular hyperpermeability in diabetic rat model. J Korean Med Sci 28: 608-613.

62. Bursell SE, Takagi C, Clermont AC, Takagi H, Mori F, et al. (1997) Specific retinal diacylglycerol and protein kinase $\mathrm{C}$ beta isoform modulation mimics abnormal retinal hemodynamics in diabetic rats. Invest Ophthalmol Vis Sci 38: 2711-2720.

63. Yokota T, Ma RC, Park JY, Isshiki K, Sotiropoulos KB, et al. (2003) Role of protein kinase $\mathrm{C}$ on the expression of platelet-derived growth factor and 
endothelin-1 in the retina of diabetic rats and cultured retinal capillary pericytes. Diabetes 52: 838-845.

64. Stitt AW, Li YM, Gardiner TA, Bucala R, Archer DB, et al. (1997) Advanced glycation end products (AGEs) co-localize with AGE receptors in the retinal vasculature of diabetic and of AGE-infused rats. Am J Pathol 150: 523-531.

65. Obrosova IG, Van HC, Fathallah L, Cao XC, Greene DA et al. (2002) An aldose reductase inhibitor reverses early diabetes-induced changes in peripheral nerve function, metabolism, and antioxidative defense. FASEB J 16: 123-125.

66. Dagher Z, Park YS, Asnaghi V, Hoehn T, Gerhardinger C et al. (2004) Studies of rat and human retinas predict a role for the polyol pathway in human diabetic retinopathy. Diabetes 53: 2404-2411.

67. Hernández C, Simó-Servat O, Simó R (2014) Somatostatin and diabetic retinopathy: current concepts and new therapeutic perspectives. Endocrine 46: 209-214.

68. Matteucci A, Gaddini L, Villa M, Varano M, Parravano M, et al. (2014) Neuroprotection by rat Müller glia against high glucose-induced neurodegeneration through a mechanism involving ERK1/2 activation. Exp Eye Res 125: 20-29.

69. Antonetti DA, Barber AJ, Khin S, Lieth E, Tarbell JM, et al. (1998) Vascular permeability in experimental diabetes is associated with reduced endothelial occludin content: vascular endothelial growth factor decreases occludin in retinal endothelial cells. Penn State Retina Research Group. Diabetes 47: 1953-1959.

70. Rungger-Brändle E, Dosso AA, Leuenberger PM (2000) Glial reactivity, an early feature of diabetic retinopathy. Invest Ophthalmol Vis Sci 41 1971-1980.

71. Zhang SX, Ma JX, Sima J, Chen Y, Hu MS, et al. (2005) Genetic difference in susceptibility to the blood-retina barrier breakdown in diabetes and oxygen-induced retinopathy. Am J Pathol 166: 313-321.

72. Kern TS, Miller CM, Du Y, Zheng L, Mohr S, et al. (2007) Topical administration of nepafenac inhibits diabetes-induced retinal microvascular disease and underlying abnormalities of retinal metabolism and physiology. Diabetes 56: 373-379.

73. Abdouh M, Talbot S, Couture R, Hasséssian HM (2008) Retinal plasma extravasation in streptozotocin-diabetic rats mediated by kinin $\mathrm{B}(1)$ and $\mathrm{B}(2)$ receptors. Br J Pharmacol 154: 136-143.

74. Pfister F, Feng Y, vom Hagen F, Hoffmann S, Molema G, et al. (2008) Pericyte migration: a novel mechanism of pericyte loss in experimental diabetic retinopathy. Diabetes 57: 2495-2502.

75. Zhang J, Wu Y, Jin Y, Ji F, Sinclair SH, et al. (2008) Intravitreal injection of erythropoietin protects both retinal vascular and neuronal cells in early diabetes. Invest Ophthalmol Vis Sci 49: 732-742.

76. Hammes HP, Feng Y, Pfister F, Brownlee M (2011) Diabetic retinopathy: targeting vasoregression. Diabetes 60: 9-16.

77. Pouliot M, Hétu S, Lahjouji K, Couture R, Vaucher E (2011) Modulation of retinal blood flow by kinin Bâ, receptor in Streptozotocin-diabetic rats. Exp Eye Res 92: 482-489.

78. Gong CY, Lu B, Hu QW, Ji LL (2013) Streptozotocin induced diabetic retinopathy in rat and the expression of vascular endothelial growth factor and its receptor. Int J Ophthalmol 6: 573-577.

79. Yan HT, Su GF (2014) Expression and significance of HIF-1 $\hat{\mathrm{I}} \pm$ and VEGF in rats with diabetic retinopathy. Asian Pac J Trop Med 7: 237-240.

80. Mancini JE, Ortiz G, Croxatto JO, Gallo JE (2013) Retinal upregulation of inflammatory and proangiogenic markers in a model of neonatal diabetic rats fed on a high-fat-diet. BMC Ophthalmol 13: 14.

81. Qaum T, Xu Q, Joussen AM, Clemens MW, Qin W, et al. (2001) VEGFinitiated blood-retinal barrier breakdown in early diabetes. Invest Ophthalmol Vis Sci 42: 2408-2413.

82. Cao J, Song H, Liu Y, Renard RA, Lobov IB, et al. (2006) Intravitreal administration of vegf trap suppresses vascular leak in the retinas of diabetic rats. Invest Ophthalmol Vis Sci 47: 1745.
83. Navaratna D, McGuire PG, Menicucci G, Das A (2007) Proteolytic degradation of VE-cadherin alters the blood-retinal barrier in diabetes. Diabetes 56: 2380-2387.

84. Shyong MP, Lee FL, Kuo PC, Wu AC, Cheng HC, et al. (2007) Reduction of experimental diabetic vascular leakage by delivery of angiostatin with a recombinant adeno-associated virus vector. Mol Vis 13: 133-141.

85. Wright WS, McElhatten RM, Messina JE, Harris NR (2010) Hypoxia and the expression of HIF-1alpha and HIF-2alpha in the retina of streptozotocin-injected mice and rats. Exp Eye Res 90: 405-412.

86. Su L, Ji J, Bian J, Fu Y, Ge Y, et al. (2012) Tacrolimus (FK506) prevents early retinal neovascularization in streptozotocin-induced diabetic mice. Int Immunopharmacol 14: 606-612.

87. Shen JH, Ma Q, Shen SR, Xu GT, Das UN (2013) Effect of Ît-linolenic acid on streptozotocin-induced diabetic retinopathy indices in vivo. Arch Med Res 44: 514-520.

88. Wang J, Xu X, Elliott MH, Zhu M, Le YZ (2010) Müller cell-derived VEGF is essential for diabetes-induced retinal inflammation and vascular leakage. Diabetes 59: 2297-2305.

89. Miyamoto K, Khosrof S, Bursell SE, Rohan R, Murata T, et al. (1999) Prevention of leukostasis and vascular leakage in streptozotocin-induced diabetic retinopathy via intercellular adhesion molecule-1 inhibition. Proc Natl Acad Sci U S A 96: 10836-10841.

90. Asnaghi V, Gerhardinger C, Hoehn T, Adeboje A, Lorenzi M (2003) A role for the polyol pathway in the early neuroretinal apoptosis and glial changes induced by diabetes in the rat. Diabetes 52: 506-511.

91. Hamada Y, Araki N, Koh N, Nakamura J, Horiuchi S, et al. (1996) Rapid formation of advanced glycation end products by intermediate metabolites of glycolytic pathway and polyol pathway. Biochem Biophys Res Commun 228: 539-543.

92. Hirata C, Nakano K, Nakamura N, Kitagawa Y, Shigeta H, et al. (1997) Advanced glycation end products induce expression of vascular endothelial growth factor by retinal Muller cells. Biochem Biophys Res Commun 236: 712-715.

93. Kandarakis SA, Piperi C, Topouzis F, Papavassiliou AG (2014) Emerging role of advanced glycation-end products (AGEs) in the pathobiology of eye diseases. Prog Retin Eye Res 42: 85-102.

94. Kuiper EJ, Van ZR, Roestenberg P, Lyons KM, Goldschmeding R, et al. (2008) Connective tissue growth factor is necessary for retinal capillary basal lamina thickening in diabetic mice. J Histochem. Cytochem. 56: 785-792.

95. Zhang B, Zhou KK, Ma JX (2010) Inhibition of connective tissue growth factor overexpression in diabetic retinopathy by SERPINA3K via blocking the WNT/beta-catenin pathway. Diabetes 59: 1809-1816.

96. Barber AJ, Antonetti DA (2003) Mapping the blood vessels with paracellular permeability in the retinas of diabetic rats. Invest Ophthalmol Vis Sci 44: 5410-5416.

97. Hammes HP (2004) [Diabetic retinopathy. Internal medical aspects of an ophthalmologic topic]. Ophthalmologe 101: 1159-1164.

98. Skondra D, Noda K, Almulki L, Tayyari F, Frimmel S, et al. (2008) Characterization of azurocidin as a permeability factor in the retina: involvement in VEGF-induced and early diabetic blood-retinal barrier breakdown. Invest Ophthalmol Vis Sci 49: 726-731.

99. Trichonas G, Manola A, Morizane Y, Thanos A, Koufomichali X, et al. (2010) A novel nonradioactive method to evaluate vascular barrier breakdown and leakage. Invest Ophthalmol Vis Sci 51: 1677-1682.

100. Anand-Apte B, Ebrahem Q, Cutler A, Farage E, Sugimoto M, et al. (2010) Betacellulin induces increased retinal vascular permeability in mice. PLoS One 5: e13444.

101. Sugimoto M, Cutler A, Shen B, Moss SE, Iyengar SK, et al. (2013) Inhibition of EGF signaling protects the diabetic retina from insulininduced vascular leakage. Am J Pathol 183: 987-995.

102. Descamps FJ, Martens E, Ballaux F, Geboes K, Opdenakker G (2004) In vivo activation of gelatinase B/MMP-9 by trypsin in acute pancreatitis is a permissive factor in streptozotocin-induced diabetes. J Pathol 204: 555-561. 
103. Ventura-Sobrevilla J, Boone-Villa VD, Aguilar CN, Román-Ramos R, Vega-Avila E, et al. (2011) Effect of varying dose and administration of streptozotocin on blood sugar in male CD1 mice. Proc West Pharmacol Soc 54: 5-9.

104. Santulli RJ, Kinney WA, Ghosh S, Decorte BL, Liu L, et al. (2008) Studies with an orally bioavailable alpha $\mathrm{V}$ integrin antagonist in animal models of ocular vasculopathy: retinal neovascularization in mice and retinal vascular permeability in diabetic rats. J Pharmacol Exp Ther 324: 894-901.

105. Nakajima M, Cooney MJ, Tu AH, Chang KY, Cao J, et al. (2001) Normalization of retinal vascular permeability in experimental diabetes with genistein. Invest Ophthalmol Vis Sci 42: 2110-2114.

106. Rangasamy S, McGuire PG, Franco NC, Monickaraj F, Oruganti SR, et al. (2014) Chemokine mediated monocyte trafficking into the retina: role of inflammation in alteration of the blood-retinal barrier in diabetic retinopathy. PLoS One 9: e108508.

107. Scheppke L, Aguilar E, Gariano RF, Jacobson R, Hood J, et al. (2008) Retinal vascular permeability suppression by topical application of a novel VEGFR2/Src kinase inhibitor in mice and rabbits. J Clin Invest 118 2337-2346.

108. Kim JH, Kim JH, Yu YS, Cho CS, Kim KW (2009) Blockade of angiotensin II attenuates VEGF-mediated blood-retinal barrier breakdown in diabetic retinopathy. J Cereb Blood Flow Metab 29: 621-628.

109. Kim JH, Kim JH, Yu YS, Shin JY, Lee HY, et al. (2008) Deguelin inhibits retinal neovascularization by down-regulation of HIF-1alpha in oxygeninduced retinopathy. J Cell Mol Med 12: 2407-2415.

110. Ibrahim AS, Elshafey S, Sellak H, Hussein KA, El-Sherbiny M, et al. (2015) A lipidomic screen of hyperglycemia-treated HRECs links 12/15Lipoxygenase to microvascular dysfunction during diabetic retinopathy via NADPH oxidase. J Lipid Res 56: 599-611.

111. Hawkins BT, Lundeen TF, Norwood KM, Brooks HL, Egleton RD (2007) Increased blood-brain barrier permeability and altered tight junctions in experimental diabetes in the rat: contribution of hyperglycaemia and matrix metalloproteinases. Diabetologia 50: 202-211.

112. Yu Z, Gong C, Lu B, Yang L, Sheng Y, et al. (2015) Dendrobium chrysotoxum Lindl. alleviates diabetic retinopathy by preventing retinal inflammation and tight junction protein decrease. J Diabetes Res 2015 518317.

113. Aiello LP, Bursell SE, Clermont A, Duh E, Ishii H, et al. (1997) Vascular endothelial growth factor-induced retinal permeability is mediated by protein kinase $\mathrm{C}$ in vivo and suppressed by an orally effective betaisoform-selective inhibitor. Diabetes 46: 1473-1480.

114. Gao BB, Clermont A, Rook S, Fonda SJ, Srinivasan VJ, et al. (2007) Extracellular carbonic anhydrase mediates hemorrhagic retinal and cerebral vascular permeability through prekallikrein activation. Nat Med 13: 181-188.

115. Phipps JA, Clermont AC, Sinha S, Chilcote TJ, Bursell SE, et al. (2009) Plasma kallikrein mediates angiotensin II type 1 receptor-stimulated retinal vascular permeability. Hypertension 53: 175-181.

116. Clermont A, Chilcote TJ, Kita T, Liu J, Riva P, et al. (2011) Plasma kallikrein mediates retinal vascular dysfunction and induces retinal thickening in diabetic rats. Diabetes 60: 1590-1598.

117. Antony BJ, Jeong W, Abramoff MD, Vance J, Sohn EH, et al. (2014) Automated 3D Segmentation of Intraretinal Surfaces in SD-OCT Volumes in Normal and Diabetic Mice. Transl Vis Sci Technol 3: 8.

118. Alam NM, Mills WC, Wong AA, Douglas RM, Szeto HH, et al. (2015) A mitochondrial therapeutic reverses visual decline in mouse models of diabetes. Dis Model Mech 8: 701-710.

119. Rakoczy EP, Ali Rahman IS, Binz N, Li CR, Vagaja NN, et al. (2010) Characterization of a mouse model of hyperglycemia and retinal neovascularization. Am J Pathol 177: 2659-2670.

120. Barber AJ, Antonetti DA, Kern TS, Reiter CE, Soans RS, et al. (2005) The Ins2Akita mouse as a model of early retinal complications in diabetes. Invest Ophthalmol Vis Sci 46: 2210-2218.
121. Han Z, Guo J, Conley SM, Naash MI (2013) Retinal angiogenesis in the Ins2(Akita) mouse model of diabetic retinopathy. Invest Ophthalmol Vis Sci 54: 574-584.

122. Rahman ISA, Li CR, Lai CM, Rakoczy EP (2011) In vivo monitoring of VEGF-induced retinal damage in the Kimba mouse model of retinal neovascularization. Curr Eye Res 36: 654-662.

123. Vagaja NN, Chinnery HR, Binz N, Kezic JM, Rakoczy EP, et al. (2012) Changes in murine hyalocytes are valuable early indicators of ocular disease. Invest Ophthalmol Vis Sci 53: 1445-1451.

124. Binz N, Ali Rahman IS, Chinnery HR, McKeone R, Simpson KM, et al. (2013) Effect of vascular endothelial growth factor upregulation on retinal gene expression in the Kimba mouse. Clin Experiment Ophthalmol 41: 251-262.

125. Lai CM, Dunlop SA, May LA, Gorbatov M, Brankov M, et al. (2005) Generation of transgenic mice with mild and severe retinal neovascularisation. Br J Ophthalmol 89: 911-916.

126. Tee LB, Penrose MA, O'Shea JE, Lai CM, Rakoczy EP et al. (2008) VEGFinduced choroidal damage in a murine model of retinal neovascularisation. Br J Ophthalmol 92: 832-838.

127. Wisniewska-Kruk J, Klaassen I, Vogels IM, Magno AL, Lai CM, et al. (2014) Molecular analysis of blood-retinal barrier loss in the Akimba mouse, a model of advanced diabetic retinopathy. Exp Eye Res 122: 123-131.

128. Rahman ISA (2011) Characterisation of the Akimba mouse: a model of retinal neovascularisation on a hyperglycaemic background and the in vivo study of Endothelin-2 in the development of neovascularisation. The University of Western Australia Centre for Ophthalmology and Visual Science.

129. Wilson CA, Fleckenstein JL, Berkowitz BA, Green ME (1992) Preretinal neovascularization in diabetic retinopathy: a preliminary investigation using contrast-enhanced magnetic resonance imaging. J Diabetes Complications 6: 223-229.

130. Tobe T, Ortega S, Luna JD, Ozaki H, Okamoto N, et al. (1998) Targeted disruption of the FGF2 gene does not prevent choroidal neovascularization in a murine model. Am J Pathol 153: 1641-1646.

131. Saishin Y, Saishin Y, Takahashi K, Lima e Silva, Hylton D, et al. (2003) VEGF-TRAP(R1R2) suppresses choroidal neovascularization and VEGFinduced breakdown of the blood-retinal barrier. J Cell Physiol 195: 241-248.

132. Yoshida T, Zhang H, Iwase T, Shen J, Semenza GL, et al. (2010) Digoxin inhibits retinal ischemia-induced HIF-1alpha expression and ocular neovascularization. FASEB J 24: 1759-1767.

133. Hara C, Kasai A, Gomi F, Satooka T, Sakimoto S, et al. (2013) Laserinduced choroidal neovascularization in mice attenuated by deficiency in the apelin-APJ system. Invest Ophthalmol Vis Sci 54: 4321-4329.

134. Oladipupo SS, Smith C, Santeford A, Park C, Sene A, et al. (2014) Endothelial cell FGF signaling is required for injury response but not for vascular homeostasis. Proc Natl Acad Sci USA 111: 13379-13384.

135. Hollanders K, Van Bergen T, Kindt N, Castermans K, Leysen D, et al. (2015) The effect of AMA0428, a novel and potent ROCK inhibitor, in a model of neovascular age-related macular degeneration. Invest Ophthalmol Vis Sci 56: 1335-1348.

136. Van de VS, Stalmans I, Heindryckx F, Oura H, Tijeras-Raballand A, et al. (2010) Further pharmacological and genetic evidence for the efficacy of PlGF inhibition in cancer and eye disease. Cell 141: 178-190.

137. Xu J, Zhu D, Sonoda S, He S, Spee C, et al. (2012) Over-expression of BMP4 inhibits experimental choroidal neovascularization by modulating VEGF and MMP-9. Angiogenesis 15: 213-227.

138. Marneros AG, She H, Zambarakji H, Hashizume H, Connolly EJ, et al. (2007) Endogenous endostatin inhibits choroidal neovascularization. FASEB J 21: 3809-3818.

139. Izumi-Nagai K, Nagai N, Ozawa Y, Mihara M, Ohsugi Y, et al. (2007) Interleukin-6 receptor-mediated activation of signal transducer and activator of transcription-3 (STAT3) promotes choroidal neovascularization. Am J Pathol 170: 2149-2158. 
140. Shi X, Semkova I, Muther PS, Dell S, Kociok N, et al. (2006) Inhibition of TNF-alpha reduces laser-induced choroidal neovascularization. Exp Eye Res 83: 1325-1334.

141. Liu J, Jha P, Lyzogubov VV, Tytarenko RG, Bora NS, et al. (2011) Relationship between complement membrane attack complex, chemokine (C-C motif) ligand 2 (CCL2) and vascular endothelial growth factor in mouse model of laser-induced choroidal neovascularization. J Biol Chem 286: 20991-21001.

142. Xie P, Kamei M, Suzuki M, Matsumura N, Nishida K, et al. (2011) Suppression and regression of choroidal neovascularization in mice by a novel CCR2 antagonist, INCB3344. PLoS One 6: e28933.

143. Lu H, Lu Q, Gaddipati S, Kasetti RB, Wang W, et al. (2014) IKK2 inhibition attenuates laser-induced choroidal neovascularization. PLoS One 9: e87530.

144. Sakurai E, Taguchi H, Anand A, Ambati BK, Gragoudas ES, et al. (2003) Targeted disruption of the CD18 or ICAM-1 gene inhibits choroidal neovascularization. Invest Ophthalmol Vis Sci 44: 2743-2749.

145. Camelo S, Raoul W, Lavalette S, Calippe B, Cristofaro B, et al. (2012) Delta-like 4 inhibits choroidal neovascularization despite opposing effects on vascular endothelium and macrophages. Angiogenesis 15: 609-622.

146. Horie S, Robbie SJ, Liu J, Wu WK, Ali RR, et al. (2013) CD200R signaling inhibits pro-angiogenic gene expression by macrophages and suppresses choroidal neovascularization. Sci Rep 3: 3072.

147. Takata S, Masuda T, Nakamura S, Kuchimaru T, Tsuruma K, et al. (2015) The effect of triamcinolone acetonide on laser-induced choroidal neovascularization in mice using a hypoxia visualization bio-imaging probe. Sci Rep 5: 9898.

148. Du H, Sun X, Guma M, Luo J, Ouyang H, et al. (2013) JNK inhibition reduces apoptosis and neovascularization in a murine model of agerelated macular degeneration. Proc Natl Acad Sci USA 110: 2377-2382.

149. Hara R, Inomata Y, Kawaji T, Sagara N, Inatani M, et al. (2010) Suppression of choroidal neovascularization by $\mathrm{N}$-acetyl-cysteine in mice. Curr Eye Res 35: 1012-1020.

150. Roggia MF, Imai H, Shiraya T, Noda Y, Ueta T (2014) Protective role of glutathione peroxidase 4 in laser-induced choroidal neovascularization in mice. PLoS One 9: e98864.

151. Zhang H, Yang Y, Takeda A, Yoshimura T, Oshima Y, et al. (2013) A novel platelet-activating factor receptor antagonist inhibits choroidal neovascularization and subretinal fibrosis. PLoS One 8: e68173.

152. Van Bergen T, Spangler R, Marshall D, Hollanders K, Van de Veire S, et al. (2015) The Role of LOX and LOXL2 in the Pathogenesis of an Experimental Model of Choroidal Neovascularization. Invest Ophthalmol Vis Sci 56: 5280-5289.

153. Nakama T, Yoshida S, Ishikawa K, Kobayashi Y, Zhou Y, et al. (2015) Inhibition of choroidal fibrovascular membrane formation by new class of RNA interference therapeutic agent targeting periostin. Gene Ther 22: 127-137.

154. Lambert V, Lecomte J, Hansen S, Blacher S, Gonzalez ML, et al. (2013) Laser-induced choroidal neovascularization model to study age-related macular degeneration in mice. Nat Protoc 8: 2197-2211.

155. Hoerster R, Muether PS, Vierkotten S, Schroder S, Kirchhof B, et al. (2012) In-vivo and ex-vivo characterization of laser-induced choroidal neovascularization variability in mice. Graefes Arch Clin Exp Ophthalmol 250: 1579-1586.

156. Zhu Y, Lu Q, Shen J, Zhang L, Gao Y, et al. (2014) Improvement and optimization of standards for a preclinical animal test model of laser induced choroidal neovascularization. PLoS One 9: e94743.

157. Poor SH, Qiu Y, Fassbender ES, Shen S, Woolfenden A, et al. (2014) Reliability of the mouse model of choroidal neovascularization induced by laser photocoagulation. Invest Ophthalmol Vis Sci 55: 6525-6534.

158. Lee J, Park DY, Park dY, Park I, Chang W, et al. (2014) Angiopoietin-1 suppresses choroidal neovascularization and vascular leakage. Invest Ophthalmol Vis Sci 55: 2191-2199.
159. Semkova I, Kociok N, Karagiannis D, Nischt R, Smyth N, et al. (2014) Anti-angiogenic effect of the basement membrane protein nidogen-1 in a mouse model of choroidal neovascularization. Exp Eye Res 118: 80-88.

160. Yanai R, Mulki L, Hasegawa E, Takeuchi K, Sweigard H, et al. (2014) Cytochrome P450-generated metabolites derived from omega-3 fatty acids attenuate neovascularization. Proc Natl Acad Sci USA 111: 9603-9608.

161. Xie P, Zhang W, Yuan S, Chen Z, Yang Q, et al. (2012) Suppression of experimental choroidal neovascularization by curcumin in mice. PLoS One 7: e53329.

162. Yu HG, Liu X, Kiss S, Connolly E, Gragoudas ES, et al. (2008) Increased choroidal neovascularization following laser induction in mice lacking lysyl oxidase-like 1. Invest Ophthalmol Vis Sci 49: 2599-2605.

163. Giani A, Thanos A, Roh MI, Connolly E, Trichonas G, et al. (2011) In vivo evaluation of laser-induced choroidal neovascularization using spectral-domain optical coherence tomography. Invest Ophthalmol Vis Sci 52: 3880-3887.

164. Cunea A, Meyer J, Russmann C, Licha K, Welker P, et al. (2014) In vivo imaging with a fundus camera in a rat model of laser-induced choroidal neovascularization. Ophthalmologica 231: 117-123.

165. Patz A (1982) Clinical and experimental studies on retinal neovascularization. XXXIX Edward Jackson Memorial Lecture. Am J Ophthalmol 94: 715-743.

166. Heidary G, Vanderveen D, Smith LE (2009) Retinopathy of prematurity: current concepts in molecular pathogenesis. Semin Ophthalmol 24: 77-81.

167. Smith LE, Wesolowski E, McLellan A, Kostyk SK, D'Amato R, et al. (1994) Oxygen-induced retinopathy in the mouse. Invest Ophthalmol Vis Sci 35: 101-111.

168. Stahl A, Chen J, Sapieha P, Seaward MR, Krah NM, et al. (2010) Postnatal weight gain modifies severity and functional outcome of oxygen-induced proliferative retinopathy. Am J Pathol 177: 2715-2723.

169. Scott A, Fruttiger M (2010) Oxygen-induced retinopathy: a model for vascular pathology in the retina. Eye (Lond) 24: 416-421.

170. Ozaki H, Yu AY, Della N, Ozaki K, Luna JD, et al. (1999) Hypoxia inducible factor-1alpha is increased in ischemic retina: temporal and spatial correlation with VEGF expression. Invest Ophthalmol Vis Sci 40: 182-189.

171. Morita M, Ohneda O, Yamashita T, Takahashi S, Suzuki N, et al. (2003) HLF/HIF-2alpha is a key factor in retinopathy of prematurity in association with erythropoietin. ЕMBO J 22: 1134-1146.

172. Brafman A, Mett I, Shafir M, Gottlieb H, Damari G, et al. (2004) Inhibition of oxygen-induced retinopathy in RTP801-deficient mice. Invest Ophthalmol Vis Sci 45: 3796-3805.

173. Kim JH, Yu YS, Shin JY, Lee HY, Kim KY, et al. (2008) Deguelin inhibits retinal neovascularization by down-regulation of HIF-1alpha in oxygeninduced retinopathy. J Cell Mol Med 12: 2407-2415.

174. Pierce EA, Foley ED, Smith LE (1996) Regulation of vascular endothelial growth factor by oxygen in a model of retinopathy of prematurity. Arch Ophthalmol 114: 1219-1228.

175. Stone J, Itin A, Alon T, Pe'er J, Gnessin H, et al. (1995) Development of retinal vasculature is mediated by hypoxia-induced vascular endothelial growth factor (VEGF) expression by neuroglia. J Neurosci 15: 4738-4747.

176. Chan-Ling T, Gock B, Stone J (1995) The effect of oxygen on vasoformative cell division. Evidence that 'physiological hypoxia' is the stimulus for normal retinal vasculogenesis. Invest Ophthalmol Vis Sci 36: 1201-1214.

177. Ishihama $\mathrm{H}$, Ohbayashi $\mathrm{M}$, Kurosawa $\mathrm{N}$, Kitsukawa $\mathrm{T}$, Matsuura $\mathrm{O}$, et al. (2001) Colocalization of neuropilin-1 and Flk-1 in retinal neovascularization in a mouse model of retinopathy. Invest Ophthalmol Vis Sci 42: 1172-1178.

178. Shi X, Zhao M, Xie WK, Liang JH, Miao YF, et al. (2013) Inhibition of neovascularization and expression shift of pro-/anti-angiogenic vascular endothelial growth factor isoforms after intravitreal bevacizumab 
injection in oxygen-induced-retinopathy mouse model. Chin Med J (Engl) 126: 345-352.

179. Rabinowitz R, Priel A, Rosner M, Pri-Chen S, Spierer A (2012) Avastin treatment reduces retinal neovascularization in a mouse model of retinopathy of prematurity. Curr Eye Res 37: 624-629.

180. Feng F, Cheng Y, Liu QH (2014) Bevacizumab treatment reduces retinal neovascularization in a mouse model of retinopathy of prematurity. Int J Ophthalmol 7: 608-613.

181. Tokunaga CC, Mitton KP, Dailey W, Massoll C, Roumayah K, et al. (2014) Effects of anti-VEGF treatment on the recovery of the developing retina following oxygen-induced retinopathy. Invest Ophthalmol Vis Sci 55: 1884-1892.

182. Beaulieu MJ (2012) Bevacizumab (avastin) for the treatment of retinopathy of prematurity. Neonatal Netw 31: 242-247.

183. Rotschild T, Nandgaonkar BN, Yu K, Higgins RD (1999) Dexamethasone reduces oxygen induced retinopathy in a mouse model. Pediatr Res 46: 94-100.

184. Akkoyun I, Yilmaz G, Oto S, Kahraman B, Haberal N, et al. (2007) Impact of triamcinolone acetonide on retinal endothelial cells in a retinopathy of prematurity mouse model. Acta Ophthalmol Scand 85: 791-794.

185. Smith LE, Shen W, Perruzzi C, Soker S, Kinose F, et al. (1999) Regulation of vascular endothelial growth factor-dependent retinal neovascularization by insulin-like growth factor-1 receptor. Nat Med 5: 1390-1395.

186. Fukuda R, Hirota K, Fan F, Jung YD, Ellis LM, et al. (2002) Insulin-like growth factor 1 induces hypoxia-inducible factor 1-mediated vascular endothelial growth factor expression, which is dependent on MAP kinase and phosphatidylinositol 3-kinase signaling in colon cancer cells. J Biol Chem 277: 38205-38211.

187. Hellstrom A, Perruzzi C, Ju M, Engstrom E, Hard AL, et al. (2001) Low IGF-I suppresses VEGF-survival signaling in retinal endothelial cells: direct correlation with clinical retinopathy of prematurity. Proc Natl Acad Sci U S A 98: 5804-5808.

188. Riecke B, Chavakis E, Bretzel RG, Linn T, Preissner KT, et al. (2001) Topical application of integrin antagonists inhibits proliferative retinopathy. Horm Metab Res 33: 307-311.

189. Wilkinson-Berka JL, Jones D, Taylor G, Jaworski K, Kelly DJ, et al. (2006) SB-267268, a nonpeptidic antagonist of alpha(v)beta3 and alpha(v)beta5 integrins, reduces angiogenesis and VEGF expression in a mouse model of retinopathy of prematurity. Invest Ophthalmol Vis Sci 47: 1600-1605.

190. Wilkinson-Berka JL, Alousis NS, Kelly DJ, Gilbert RE (2003) COX-2 inhibition and retinal angiogenesis in a mouse model of retinopathy of prematurity. Invest Ophthalmol Vis Sci 44: 974-979.

191. Liu NN, Sun YZ, Zhao N, Chen L (2015) Rofecoxib inhibits retinal neovascularization via down regulation of cyclooxygenase- 2 and vascular endothelial growth factor expression. Clin Experiment Ophthalmol 43: 458-465.

192. Di Y, Zhang Y, Yang H, Wang A, Chen X (2015) The mechanism of CCN1-enhanced retinal neovascularization in oxygen-induced retinopathy through PI3K/Akt-VEGF signaling pathway. Drug Des Devel Ther 9: 2463-2473.

193. Watanabe D, Suzuma K, Matsui S, Kurimoto M, Kiryu J, et al. (2005) Erythropoietin as a retinal angiogenic factor in proliferative diabetic retinopathy. N Engl J Med 353: 782-792.

194. Brooks SE, Gu X, Samuel S, Marcus DM, Bartoli M, et al. (2001) Reduced severity of oxygen-induced retinopathy in eNOS-deficient mice. Invest Ophthalmol Vis Sci 42: 222-228.

195. He T, Ai M, Zhao XH, Xing YQ (2007) Inducible nitric oxide synthase mediates hypoxia-induced hypoxia-inducible factor-1 alpha activation and vascular endothelial growth factor expression in oxygen-induced retinopathy. Pathobiology 74: 336-343.

196. Kasai A, Shintani N, Oda M, Kakuda M, Hashimoto H, et al. (2004) Apelin is a novel angiogenic factor in retinal endothelial cells. Biochem Biophys Res Commun 325: 395-400.
197. Lutty GA, McLeod DS (2003) Retinal vascular development and oxygeninduced retinopathy: a role for adenosine. Prog Retin Eye Res 22: 95-111.

198. Liu XL, Zhou R, Pan QQ, Jia XL, Gao WN, et al. (2010) Genetic inactivation of the adenosine $\mathrm{A} 2 \mathrm{~A}$ receptor attenuates pathologic but not developmental angiogenesis in the mouse retina. Invest Ophthalmol Vis Sci 51: 6625-6632.

199. Saint-Geniez M, Ghelfi E, Liang X, Yu C, Spencer C, et al. (2014) Fatty acid binding protein 4 deficiency protects against oxygen-induced retinopathy in mice. PLoS One 9: e96253.

200. Guimaraes S, Moura D (2001) Vascular adrenoceptors: an update. Pharmacol Rev 53: 319-356.

201. Iaccarino G, Ciccarelli M, Sorriento D, Galasso G, Campanile A, et al. (2005) Ischemic neoangiogenesis enhanced by beta2-adrenergic receptor overexpression: a novel role for the endothelial adrenergic system. Circ Res 97: 1182-1189.

202. Makhoul IR, Peleg O, Miller B, Bar-Oz B, Kochavi O, et al. (2013) Oral propranolol versus placebo for retinopathy of prematurity: a pilot, randomised, double-blind prospective study. Arch Dis Child 98: 565-567.

203. Filippi L, Cavallaro G, Bagnoli P, Dal MM, Fiorini P, et al. (2013) Oral propranolol for retinopathy of prematurity: risks, safety concerns, and perspectives. J Pediatr 163: 1570-1577.

204. Huang H, Shen J, Vinores SA (2011) Blockade of VEGFR1 and 2 suppresses pathological angiogenesis and vascular leakage in the eye. PLoS One 6: e21411.

205. Huang H, Van de Veire S, Dalal M, Parlier R, Semba RD, et al. (2011) Reduced retinal neovascularization, vascular permeability, and apoptosis in ischemic retinopathy in the absence of prolyl hydroxylase- 1 due to the prevention of hyperoxia-induced vascular obliteration. Invest Ophthalmol Vis Sci 52: 7565-7573.

206. Wang L, Shi P, Xu Z, Li J, Xie Y, et al. (2014) Up-regulation of VEGF by retinoic acid during hyperoxia prevents retinal neovascularization and retinopathy. Invest Ophthalmol Vis Sci 55: 4276-4287.

207. Kusari J, Padillo E, Zhou SX, Bai Y, Wang J, et al. (2011) Effect of brimonidine on retinal and choroidal neovascularization in a mouse model of retinopathy of prematurity and laser-treated rats. Invest Ophthalmol Vis Sci 52: 5424-5431.

208. Oliner JD, Bready J, Nguyen L, Estrada J, Hurh E, et al. (2012) AMG 386 , a selective angiopoietin 1/2-neutralizing peptibody, inhibits angiogenesis in models of ocular neovascular diseases. Invest Ophthalmol Vis Sci 53: 2170-2180.

209. Lee J, Kim KE, Choi DK, Jang JY, Jung JJ, et al. (2013) Angiopoietin-1 guides directional angiogenesis through integrin alphavbeta5 signaling for recovery of ischemic retinopathy. Sci Transl Med 5: 203ra127.

210. Dorrell MI, Aguilar E, Jacobson R, Trauger SA, Friedlander J, et al. (2010) Maintaining retinal astrocytes normalizes revascularization and prevents vascular pathology associated with oxygen-induced retinopathy. Glia 58: 43-54.

211. Sennlaub F, Courtois Y, Goureau O (2002) Inducible nitric oxide synthase mediates retinal apoptosis in ischemic proliferative retinopathy. J Neurosci 22: 3987-3993.

212. Downie LE, Pianta MJ, Vingrys AJ, Wilkinson-Berka JL, Fletcher EL (2007) Neuronal and glial cell changes are determined by retinal vascularization in retinopathy of prematurity. J Comp Neurol 504: 404-417.

213. Stevenson L, Matesanz N, Colhoun L, Edgar K, Devine A, et al. (2010) Reduced nitro-oxidative stress and neural cell death suggests a protective role for microglial cells in TNFalpha-/- mice in ischemic retinopathy. Invest Ophthalmol Vis Sci 51: 3291-3299.

214. Fu Z, Nian S, Li SY, Wong D, Chung SK, et al. (2015) Deficiency of aldose reductase attenuates inner retinal neuronal changes in a mouse model of retinopathy of prematurity. Graefes Arch Clin Exp Ophthalmol 253: 1503-1513.

215. Narayanan SP, Suwanpradid J, Saul A, Xu Z, Still A, et al. (2011) Arginase 2 deletion reduces neuro-glial injury and improves retinal function in a model of retinopathy of prematurity. PLoS One 6: e22460. 
216. Narayanan SP, Xu Z, Putluri N, Sreekumar A, Lemtalsi T, et al. (2014) Arginase 2 deficiency reduces hyperoxia-mediated retinal neurodegeneration through the regulation of polyamine metabolism. Cell Death Dis 5: e1075.

217. Suwanpradid J, Rojas M, Behzadian MA, Caldwell RW, Caldwell RB (2014) Arginase 2 deficiency prevents oxidative stress and limits hyperoxia-induced retinal vascular degeneration. PLoS One 9: e110604.

218. Yang WJ, Hu J, Uemura A, Tetzlaff F, Augustin HG, et al. (2015) Semaphorin-3C signals through Neuropilin-1 and PlexinD1 receptors to inhibit pathological angiogenesis. EMBO Mol Med 7: 1267-1284.

219. Michan S, Juan AM, Hurst CG, Cui Z, Evans LP, et al. (2014) Sirtuin1 over-expression does not impact retinal vascular and neuronal degeneration in a mouse model of oxygen-induced retinopathy. PLoS One 9: e85031.

220. Connor KM, Krah NM, Dennison RJ, Aderman CM, Chen J, et al. (2009) Quantification of oxygen-induced retinopathy in the mouse: a model of vessel loss, vessel regrowth and pathological angiogenesis. Nat Protoc 4: 1565-1573

221. Stahl A, Connor KM, Sapieha P, Willett KL, Krah NM, et al. (2009) Computer-aided quantification of retinal neovascularization. Angiogenesis 12: 297-301

222. Ozaki H, Hayashi H, Vinores SA, Moromizato Y, Campochiaro PA, et al. (1997) Intravitreal sustained release of VEGF causes retinal neovascularization in rabbits and breakdown of the blood-retinal barrier in rabbits and primates. Exp Eye Res 64: 505-517.

223. Luna JD, Chan CC, Derevjanik NL, Mahlow J, Chiu C, et al. (1997) Blood-retinal barrier (BRB) breakdown in experimental autoimmune uveoretinitis: comparison with vascular endothelial growth factor, tumor necrosis factor alpha, and interleukin-lbeta-mediated breakdown. J Neurosci Res 49: 268-280.

224. Alikacem N, Yoshizawa T, Nelson KD, Wilson CA (2000) Quantitative MR imaging study of intravitreal sustained release of VEGF in rabbits. Invest Ophthalmol Vis Sci 41: 1561-1569.

225. Wong CG, Rich KA, Liaw LH, Hsu HT, Berns MW (2001) Intravitreal VEGF and bFGF produce florid retinal neovascularization and hemorrhage in the rabbit. Curr Eye Res 22: 140-147.

226. Tolentino MJ, McLeod DS, Taomoto M, Otsuji T, Adamis AP, et al. (2002) Pathologic features of vascular endothelial growth factor-induced retinopathy in the nonhuman primate. Am J Ophthalmol 133: 373-385.

227. Witmer AN, Blaauwgeers HG, Weich HA, Alitalo K, Vrensen GF, et al (2002) Altered expression patterns of VEGF receptors in human diabetic retina and in experimental VEGF-induced retinopathy in monkey. Invest Ophthalmol Vis Sci 43: 849-857.

228. Miyamoto N, de KY, Normand N, Courtois Y, Jeanny JC, et al. (2008) PIGF-1 and VEGFR-1 pathway regulation of the external epithelial hemato-ocular barrier. A model for retinal edema. Ophthalmic Res 40: 203-207.

229. Miyamoto K, Khosrof S, Bursell SE, Moromizato Y, Aiello LP, et al. (2000) Vascular endothelial growth factor (VEGF)-induced retinal vascular permeability is mediated by intercellular adhesion molecule-1 (ICAM-1). Am J Pathol 156: 1733-1739.

230. Arana LA, Pinto AT, Chader GJ, Barbosa JD, Morales S, et al. (2012) Fluorescein angiography, optical coherence tomography, and histopathologic findings in a VEGF(165) animal model of retinal angiogenesis. Graefes Arch Clin Exp Ophthalmol 250: 1421-1428.

231. Tolentino MJ, Miller JW, Gragoudas ES, Jakobiec FA, Flynn E, et al. (1996) Intravitreous injections of vascular endothelial growth factor produce retinal ischemia and microangiopathy in an adult primate. Ophthalmology 103: 1820-1828.

232. Witmer AN, Vrensen GF, Van Noorden CJ, Schlingemann RO (2003) Vascular endothelial growth factors and angiogenesis in eye disease. Prog Retin Eye Res 22: 1-29.

233. Lu M, Perez VL, Ma N, Miyamoto K, Peng HB, et al. (1999) VEGF increases retinal vascular ICAM-1 expression in vivo. Invest Ophthalmol Vis Sci 40: $1808-1812$.
234. Edelman JL, Lutz D, Castro MR (2005) Corticosteroids inhibit VEGFinduced vascular leakage in a rabbit model of blood-retinal and bloodaqueous barrier breakdown. Exp Eye Res 80: 249-258.

235. Miles AA, Miles EM (1952) Vascular reactions to histamine, histamineliberator and leukotaxine in the skin of guinea-pigs. J Physiol 118: 228-257.

236. Claffey KP, Brown LF, del Aguila LF, Tognazzi K, Yeo KT, et al. (1996) Expression of vascular permeability factor/vascular endothelial growth factor by melanoma cells increases tumor growth, angiogenesis, and experimental metastasis. Cancer Res 56: 172-181.

237. Oura H, Bertoncini J, Velasco P, Brown LF, Carmeliet P, et al. (2003) A critical role of placental growth factor in the induction of inflammation and edema formation. Blood 101: 560-567.

238. Murohara T, Horowitz JR, Silver M, Tsurumi Y, Chen D, et al. (1998) Vascular endothelial growth factor/vascular permeability factor enhances vascular permeability via nitric oxide and prostacyclin. Circulation 97: 99-107.

239. Omori K, Kida T, Hori M, Ozaki H, Murata T (2014) Multiple roles of the PGE2 -EP receptor signal in vascular permeability. Br J Pharmacol 171: 4879-4889.

240. Wu MH, Ying NW, Hong TM, Chiang WF, Lin YT, et al. (2014) Galectin-1 induces vascular permeability through the neuropilin-1/ vascular endothelial growth factor receptor-1 complex. Angiogenesis 17: 839-849.

241. Huegel R, Velasco P, De la Luz SM, Christophers E, Schroder JM, et al. (2007) Novel anti-inflammatory properties of the angiogenesis inhibitor vasostatin. J Invest Dermatol 127: 65-74.

242. Inoue H, Asaka T, Nagata N, Koshihara Y (1997) Mechanism of mustard oil-induced skin inflammation in mice. Eur J Pharmacol 333: 231-240.

243. McMurdy J, Reichner J, Mathews Z, Markey M, Intwala S, et al. (2009) Broadband reflectance spectroscopy for establishing a quantitative metric of vascular leak using the Miles assay. J Biomed Opt 14: 054012.

244. Di RM, Willoughby DA (1971) Screens for anti-inflammatory drugs. J Pharm Pharmacol 23: 297-298.

245. Al-Haboubi HA, Zeitlin IJ (1983) Re-appraisal of the role of histamine in carrageenan-induced paw oedema. Eur J Pharmacol 88: 169-176.

246. Ezeamuzie CI, Umezurike CC (1989) Effect of histamine H2-receptor antagonists on acute inflammatory of the rat paw oedema. J Pharm Pharmacol 41: 261-265.

247. Rouleau A, Stark H, Schunack W, Schwartz JC (2000) Anti-inflammatory and antinociceptive properties of BP 2-94, a histamine $\mathrm{H}(3)$-receptor agonist prodrug. J Pharmacol Exp Ther 295: 219-225.

248. Albayrak A, Halici Z, Cadirci E, Polat B, Karakus E, et al. (2013) Inflammation and peripheral 5-HT7 receptors: the role of 5-HT7 receptors in carrageenan induced inflammation in rats. Eur J Pharmacol 715: 270-279.

249. Kenniston JA, Faucette RR, Martik D, Comeau SR, Lindberg AP, et al. (2014) Inhibition of plasma kallikrein by a highly specific active site blocking antibody. J Biol Chem 289: 23596-23608.

250. Riendeau D, Percival MD, Boyce S, Brideau C, Charleson S, et al. (1997) Biochemical and pharmacological profile of a tetrasubstituted furanone as a highly selective COX-2 inhibitor. Br J Pharmacol 121: 105-117.

251. Morris CJ (2003) Carrageenan-induced paw edema in the rat and mouse. Methods Mol Biol 225: 115-121.

252. Abbas SS, Schaalan MF, Bahgat AK, El-Denshary ES (2014) Possible potentiation by certain antioxidants of the anti-inflammatory effects of diclofenac in rats. ScientificWorldJournal. 2014: 731462.

253. Seibert K, Zhang Y, Leahy K, Hauser S, Masferrer J, et al. (1994) Pharmacological and biochemical demonstration of the role of cyclooxygenase 2 in inflammation and pain. Proc Natl Acad Sci USA 91: 12013-12017.

254. Park SK, Park SI, Park SM, Cho IJ, Park CI, et al. (2013) Inhibition of Acute Phase Inflammation by Laminaria japonica through Regulation of iNOS-NF- kappa B Pathway. Evid Based Complement Alternat Med 2013: 439498 . 
Citation: Reyns GE, Hu TT, Van Bergen T, Etienne I, Willekens K, et al. (2016) Selection Strategy of In Vivo Models for Ophthalmic Drug Development in Diabetic Retinopathy. J Mol Genet Med 10: 202. doi:10.4172/1747-0862.1000202

Page 18 of 18

255. Dey D, Chaskar S, Athavale N, Chitre D (2014) Inhibition of LPS-induced TNF-alpha and NO production in mouse macrophage and inflammatory response in rat animal models by a novel Ayurvedic formulation, BV-9238. Phytother Res 28: 1479-1485.

256. Salvemini D, Wang ZQ, Wyatt PS, Bourdon DM, Marino MH, et al. (1996) Nitric oxide: a key mediator in the early and late phase of carrageenan-induced rat paw inflammation. $\mathrm{Br} \mathrm{J}$ Pharmacol 118: 829-838.

257. Dudhgaonkar SP, Tandan SK, Bhat AS, Jadhav SH, Kumar D (2006) Synergistic anti-inflammatory interaction between meloxicam and aminoguanidine hydrochloride in carrageenan-induced acute inflammation in rats. Life Sci 78: 1044-1048.

258. Uzkeser H, Cadirci E, Halici Z, Odabasoglu F, Polat B, et al. (2012) Antiinflammatory and antinociceptive effects of salbutamol on acute and chronic models of inflammation in rats: involvement of an antioxidant mechanism. Mediators Inflamm 2012: 438912.

259. Sadeghi H, Hajhashemi V, Minaiyan M, Movahedian A, Talebi A (2013) Further studies on anti-inflammatory activity of maprotiline in carrageenan-induced paw edema in rat. Int Immunopharmacol 15: 505-510.

260. Nonato FR, Nogueira TM, Barros TA, Lucchese AM, Oliveira CE, et al. (2011) Antinociceptive and antiinflammatory activities of Adiantum latifolium Lam.: evidence for a role of IL-1beta inhibition. J Ethnopharmacol 136: 518-524.

261. Fereidoni M, Ahmadiani A, Semnanian S, Javan M (2000) An accurate and simple method for measurement of paw edema. J Pharmacol Toxicol Methods 43: 11-14.

262. Morris CJ (2003) Carrageenan-induced paw edema in the rat and mouse. Methods Mol Biol 225: 115-121.
263. Zeiss CJ (2010) Animals as models of age-related macular degeneration: an imperfect measure of the truth. Vet Pathol 47: 396-413.

264. Huber G, Heynen S, Imsand C, vom HF, Muehlfriedel R, et al. (2010) Novel rodent models for macular research. PLoS One 5: e13403.

265. Pennesi ME, Neuringer M, Courtney RJ (2012) Animal models of age related macular degeneration. Mol Aspects Med 33: 487-509.

266. Laude A, Tan LE, Wilson CG, Lascaratos G, Elashry M, et al. (2010) Intravitreal therapy for neovascular age-related macular degeneration and inter-individual variations in vitreous pharmacokinetics. Prog Retin Eye Res 29: 466-475.

267. Rajendram R, Fraser-Bell S, Kaines A, Michaelides M, Hamilton RD, et al. (2012) A 2-year prospective randomized controlled trial of intravitreal bevacizumab or laser therapy (BOLT) in the management of diabetic macular edema: 24-month data: report 3. Arch Ophthalmol 130: 972-979.

268. Cheung N, Mitchell P, Wong TY (2010) Diabetic retinopathy. Lancet 376: 124-136.

269. Ola MS, Alhomida AS (2014) Neurodegeneration in diabetic retina and its potential drug targets. Curr Neuropharmacol 12: 380-386.

270. Safi SZ, Qvist R, Kumar S, Batumalaie K, Ismail IS (2014) Molecular mechanisms of diabetic retinopathy, general preventive strategies, and novel therapeutic targets. Biomed Res Int 2014: 801269.

271. Mi XS, Yuan TF, Ding Y, Zhong JX, So KF (2014) Choosing preclinical study models of diabetic retinopathy: key problems for consideration. Drug Des Devel Ther 8: 2311-2319.

272. Cunha-Vaz J (2007) Characterization and relevance of different diabetic retinopathy phenotypes. Dev Ophthalmol 39: 13-30. 